\title{
Diversidad alfa y beta de la comunidad de reptiles en el complejo cenagoso de Zapatosa, Colombia
}

\author{
Guido Fabián Medina-Rangel \\ Reptiles-Grupo de Biodiversidad y Conservación, Instituto de Ciencias Naturales, Universidad Nacional de Colombia, \\ Carrera 30 No 45-03, edificio 425, oficina 307, Apartado aéreo 7495, Bogotá D.C., Colombia; gfmedinar@unal.edu. \\ co, guidofabianmedina@gmail.com
}

Recibido 23-IV-2010. C Corregido 01-XII-2010. Aceptado 03-I-2011.

\begin{abstract}
Alfa and beta diversity of reptilian assemblages in Zapatosa wetland complex, Colombia. Diversity is a property of community that can described, characterized, and understood according to the functioning of ecosystems. To study the richness and local abundance and species replacement between habitats around the Zapatosa's wetland complex (El Cesar Department), I carried out four field trips between November of 2006 and October of 2007. A total of 640 sampling hours/man analyzed five habitat types chasmophyte forest, dry forest, riparian forest, palm-grove and tree-lined savanna; with the exception of the palm-grove sampled at its $75 \%$, the others were sampled up to their $80 \%$. I found 847 reptiles that were distributed in 48 species. The group with the highest number of species was Colubridae with 14 , followed by Gekkonidae with five. Five endemic species and eight with some conservation threat grade at a national level are reported. The riparian forest was the richest and most abundant habitat with 34 species and 196 individuals. For each habitat, Colubridae had the highest number of species, followed by the families Polychrotidae, Gekkonidae and Teiidae, in that order. The reptile species composition was not different between the tree-lined savanna and the chasmophyte forest, but differed among the tree-lined savanna and the riparian forest, palm-grove and dry forest habitats. The most important differences in the species composition among almost all the habitats were influenced by the species Anolis tropidogaster and Gonatodes albogularis, and the higher occurrence of Stenocercus erythrogaster in the chasmophyte forest. The species replacement had an average value of 50\%; the biggest amounts of shared species were the lizards, while the snake Leptodeira septentrionalis was the only one present in all habitat types. The forest grows-among-rocks showed the biggest complementarity and number of unique species compared to the other habitats. The wetland complex provides two thirds of the reptile's species reported until now for the Caribbean region, and more than $80 \%$ of those reported for the El Cesar department. This wetland complex seems to behave as a center for low land species concentration as it hosts a high proportion of species from those places. Rev. Biol. Trop. 59 (2): 935-968. Epub 2011 June 01.
\end{abstract}

Key words: alpha and beta diversity, lizards, snakes, turtles and crocodiles, composition and structure, Zapatosa's wetland complex, Colombia.

La diversidad en los trópicos se asocia principalmente a complicados procesos ecológicos, filogenéticos e históricos que se han desarrollado al interior de sus ecosistemas (Ricklefs \& Schulter 1993, Greene 2005). Sin embargo, la diversidad no deja de ser una propiedad emergente de las comunidades, lo que permite aproximarse al conocimiento de los ecosistemas que los constituyen y comparar la productividad o estabilidad de los procesos internos de todo el sistema (Pielou 1975, Chapin et al. 2000) y aporta elementos tales como las relación y respuesta de las especies con su medio, para delinear la estructura de la comunidad y la conservación de sus especies, al tiempo que se convierte en herramienta para el monitorear el buen funcionamiento de un ecosistema (Magurran 1989, 2004, Moreno 2001). 
Con el fin de cuantificar la diversidad se han propuesto diferentes aproximaciones que buscan entender cómo se expresa a diferentes niveles dentro de los ecosistemas; su medición se puede desglosar y trabajar mejor dependiendo de la escala espacial. Para entender cómo cambia a distintos niveles se ha referenciado en tres componentes (Whittaker 1972, RangelCh. et al. 1997): diversidad alfa, entendida como la riqueza de especies a nivel local de una comunidad que se considera más o menos homogénea; diversidad beta como el grado de recambio o reemplazo en la composición de especies entre comunidades de un paisaje; y diversidad gama aquella riqueza de especies que integran el conjunto del paisaje.

En general, los valores más altos de abundancia y riqueza de la comunidad de reptiles se presentan en hábitats con una estructura vegetal más compleja (Garden et al. 2007), pues ofrecen una gama más amplia de recursos, que se esperaría puedan explotar un mayor número de especies, mientras que el mayor recambio de especies se exhibe entre los hábitats con la mayor diferencia en su estructura vegetal (Smith \& Ballinger 2001, Jellinek et al. 2004). Sin embargo, esta no es una condición estática: diferentes elementos intervienen para que cambie la abundancia, la riqueza y el recambio de reptiles que se presenta en los hábitats. Entre estos se encuentran su baja movilidad en general (Pough 1980), su fisiología térmica o ectotermia que limita la ocupación de diferentes ambientes (Zug et al. 2001) y genera que los reptiles respondan diferencialmente a cambios en su hábitat (Jellinek et al. 2004). Teniendo en cuenta que la diversidad de especies difiere en cada hábitat (Vargas \& Bolaños 1999, UrbinaCardona \& Londoño-Murcia 2003, August 1983, Sánchez-P et al. 1996) y que en el país hay conocimiento limitado de este tipo de relaciones (Carvajal-Cogollo \& Urbina-Cardona 2008, Cárdenas-Arévalo et al. 2010, Ayala \& Castro: documento inédito, Lagartos de Colombia/Lizards of Colombia. Volumen I-V. Colombia. 820 pp.), se hace sumamente valioso y útil el estudio de la diversidad de reptiles y otros grupos de animales en ambientes con alta presión antrópica, ante la inevitable pérdida de especies que se presenta en la actualidad (Redford 1997, Gibbons et al. 2000).

El objetivo de este trabajo es determinar la riqueza, abundancia, grado de recambio y composición de especies (diversidad alfa y beta) de la comunidad de reptiles del complejo cenagoso de Zapatosa (Colombia), comparando entre diferentes tipos de hábitat.

\section{MATERIALES Y MÉTODOS}

Área de estudio: El trabajo se desarrolló en el departamento del Cesar, en cinco tipos de hábitat alrededor de tres ciénagas pertenecientes al gran complejo cenagoso de Zapatosa, entre 40 y 180 metros de altitud. La ciénaga de Zapatosa (9 $14^{\prime} \mathrm{N}-73^{\circ} 46^{\prime} \mathrm{W}-9^{\circ} 21^{\prime} \mathrm{N}-73^{\circ} 49^{\prime}$ $\mathrm{W})$, con alrededor de 30 000ha de extensión, pertenece a los municipios de Chimichagua, el Banco y Chiriguana. La ciénaga Mata de Palma $\left(9^{\circ} 32^{\prime} \mathrm{N}-73^{\circ} 39^{\prime} \mathrm{W}\right)$, con 40 ha de extensión, se ubica en el corregimiento de Potrerillo y la ciénaga la Pachita $\left(9^{\circ} 32^{\prime} \mathrm{N}-73^{\circ} 41^{\prime} \mathrm{W}\right)$, con 10 ha de extensión, en el corregimiento de La Loma, ambas pertenecen al municipio de El Paso.

El régimen de las lluvias de la zona es bimodal tetraestacional, la precipitación media anual oscila entre $1000-2600 \mathrm{~mm}$ y un promedio de temperatura de $27^{\circ} \mathrm{C}$ (Rangel-Ch. et al. 1997, Rangel-Ch. et al. 2008a). De acuerdo con Rangel-Ch. et al. (1997), el área forma parte de la formación de Bosque Seco Tropical (BsT), la cual se caracteriza por tener terrenos con pendientes en general suaves $(2-5 \%$ en promedio para toda la formación, con algunos sitios $30 \%$ a $80 \%$ ). La cobertura vegetal dominante actualmente es la matriz de pastizales, donde se encuentran algunos fragmentos de bosque seco tropical muy aislados, bosques de ribera en un estado de conservación intermedio, rastrojo alto y bajo, palmares formados por la fuerte entresaca de madera a la cual fueron sometidos los bosques relictuales $\mathrm{y}$ potreros con algunos árboles dispersos integrando cercas vivas y sombrío para el ganado (Rangel-Ch. et al. 2008b). Entre las presiones más fuertes sobre los remanentes de vegetación 
y la fauna asociada a la misma, se encuentra la ganadería intensiva, la poda y quema frecuente para cultivo, la degradación y contaminación del suelo y el agua por basuras en los alrededores de zonas pobladas y, finalmente, la tala del bosque y entresaca de madera para venta y uso doméstico.

Hábitats estudiados: De acuerdo con la fisonomía vegetal en la zona de estudio que suministra un conjunto particular de recursos y condiciones ambientales, se definieron cinco tipos de hábitat (Barbosa-Castillo et al. 2008, Rangel-Ch. et al. 2008b): bosque casmófito (bosque seco de pendiente), bosque seco (fragmentos de bosque seco en zonas planas), bosque de ribera, palmares y sabanas arboladas (pastizales naturales y sembrados).

Bosque casmófito (bosque seco de pendiente $\boldsymbol{B P}$ ): Ubicación sitios muestreados dentro de cada hábitat: 1) municipio de Chimichagua, vereda El Cerro, cerro San Ecce Homo $9^{\circ} 17^{\prime}$ 52,9" N - 7346'41,2" W, altitud 65-210m; 2) municipio de Chimichagua, vereda Tierra Grata, finca Señor Reyes Mejía $9^{\circ} 21^{\prime} 04,7^{\prime \prime} \mathrm{N}-73^{\circ} 48^{\prime} 24,0$ ” W, altitud 50-70m.

Fisiografía: Bosque seco tropical, con sustrato pedregoso, abundante roca caliza expuesta, cantos rodados, numerosas grietas y suelo franco-arcilloso de color pardo y con menos de $10 \mathrm{~cm}$ de profundidad, pendiente entre $30-80 \%$. El microclima en general es muy seco, la vegetación en la estación seca pierde casi todas las hojas y en época de lluvias reverdece. Hábitat expuesto a constante extracción de roca para construcción, quemas regulares que se extienden sin control algunas veces, entrada de ganado constante, algunas áreas de bosque en proceso de tumba en sus alrededores y erosión por la pendiente.

Vegetación: Predomina la vegetación espinosa (cactáceas) de bajo porte entre 3-5m ("varillales"). Se diferenciaron cinco estratos, el estrato arbóreo inferior con una altura media de $14 \mathrm{~m}$ y cobertura promedio del $60 \%$, donde abundan el Sabal mauritiiformis (palma amarga), Cedrela odorata (cedro) y Attalea butyracea (palma de vino), exhibe elementos aislados más alto en el dosel entre $12-24 \mathrm{~m}$ de altura; el estrato subarbóreo tuvo alturas entre $7-9 \mathrm{~m} \mathrm{y}$ cobertura promedio del $65 \%$, donde predominan Cochlospermum vitifolium (algodoncillo), Brosimum alicastrum (guáimaro), Cavanillesia platanifolia, Dilodendron costarricense y Bauhinia glabra (bejucos); los estratos arbustivo y herbáceo con cobertura promedio del $85 \%$, son densos en algunos sectores donde predominan Spondias momin (hobo) y Astronium graveolens (gusanero); y finalmente el estrato rasante tiene elementos dispersos y cobertura promedio del $30 \%$ dominados por Guapira spp. (uvita o cotorrero) y Cathlotropis procera. La capa de hojarasca es densa y cubre entre el 40-70\% del suelo.

Fragmentos de bosque seco (BS): Ubicación sitios muestreados dentro de cada hábitat: 1) municipio de Chimichagua, vereda Democracia $9^{\circ} 17^{\prime} 52,9^{\prime \prime} \mathrm{N}-73^{\circ} 46^{\prime} 41,2$ ' W, altitud 45-59m; 2) municipio de Chimichagua, vereda Torrecilla, finca David Cerdiles 9 17 '57,8” N - 7346'25,9" W altitud 47m; 3) municipio de Chimichagua, corregimiento de Saloa, vereda Mataleón, finca Cuernavaca 908'29,6" N 734' $33,7^{\prime}$ " W altitud 50m; 4) municipio de El Paso, corregimiento de Potrerillo 9³0'10,0" $\mathrm{N}-7^{\circ} 35^{\prime} 46,6^{\prime \prime} \mathrm{W}$, altitud $42-55 \mathrm{~m}$.

Fisiografía: Fragmentos de bosque seco intervenido, con suelo desnudo de color oscuro, consistencia franco-arcillosa y con más de diez centímetros de profundidad; terreno ondulado, pendientes menores a $30 \%$. El microclima del hábitat en general es seco y parte de la vegetación en la estación seca pierde casi todas las hojas y en época de lluvias reverdece. Hábitat expuesto a fuerte proceso de poda, entresaca y tumba en los alrededores para introducción de cultivos de maíz (Zea mays), yuca (Manihot esculenta), palma de aceite (Elaeis oleifera), entre otros, además de la ganadería intensiva y extensiva. 
Vegetación: Hábitat que está organizado en cinco estratos, donde predomina el estrato arbóreo inferior con alturas entre $11-21 \mathrm{~m}$ y cobertura promedio del $90 \%$, las especies dominantes son Samanea saman (campano) y Hymenaea courbaril (algarrobo); sigue el estrato subarbóreo con una altura entre 9-11m y cobertura promedio del $80 \%$, predominan $A$. butyracea (palma de vino), $S$. mauritiiformis (palma amarga) y Acrocomia aculeata (palma corozo); el estrato arbustivos con una altura entre $5-7 \mathrm{~m}$ y cobertura promedio del $65 \%$, está representado por individuos jóvenes de A. butyracea (palma de vino), bejucos leñosos (Bignoniaceae, Leguminosae y B. glabra) y fragmentos de tallos viejos; y finalmente los estratos herbáceo y rasante tienen elementos dispersos y cobertura promedio del $50 \%$ ambos, dominados por Guapira spp. (uvita o cotorrero). La capa de hojarasca es abundante y cubrió entre el 60-80\% del suelo.

Palmar (P): Ubicación sitios muestreados dentro de cada hábitat: 1) municipio de Chimichagua, vereda Torrecillas, caño Guaraguao finca de Saúl Martínez rumbo a la vereda Los Piñones 9¹8'17,7” N - 7348'49,6” W, altitud $71 \mathrm{~m}$; 2) municipio de Chimichagua, vereda El Platanal, finca Santa Marta, caño Largo $9^{\circ} 19^{\prime} 07,1^{\prime \prime} \mathrm{N}-7^{\circ} 45^{\prime} 00,7^{\prime}$ ' W, altitud 49m; 3) municipio de El Paso, corregimiento de Potrerillo, finca Boca-e-potrero 9³2' 18,0" $\mathrm{N}-73^{\circ} 37^{\prime} 56,2$ ' W, altitud 60m; 4) municipio de El Paso, corregimiento de Potrerillo, ciénaga de Mata de Palma 9० 33'35,7" N - 7340'39,6" $\mathrm{W}$, altitud $53 \mathrm{~m}$.

Fisiografía: El hábitat se caracteriza por la presencia de especies de palma dado que la mayoría de la vegetación ha sido removida ya sea por extracción para uso o adecuación del terreno para ganadería. Este presentó suelo desnudo de consistencia franco-arenosa y con más de diez centímetros de profundidad; terreno ondulado, pendientes menores a $10 \%$. Se dio la presencia de caños que cruzan los palmares que también pueden encontrarse en el borde de la ciénaga e inundarse regularmente, sin embargo la consistencia del suelo impedía que permanecieran mucho tiempo anegados. El microclima en general es seco y parte de la vegetación remanente en la estación seca pierde casi todas las hojas y en época de lluvias reverdece. Hábitat se encuentra sometido además de la sustracción de la vegetación ya mencionada, a quemas constantes para remover el rastrojo y hacerlos accesibles para el ganado.

Vegetación: Con cinco estratos donde predomina el estrato arbóreo inferior cuyo dosel en promedio alcanza los $20 \mathrm{~m}$ y cobertura entre el $85-90 \%$, está representado por $A$. butyracea (palma de vino), Bactris guineensis (palma de lata), A. aculeata (palma de corozo) y Bactris sp. (maquenque); el estrato arbóreo superior es poco conspicuo, cobertura del $40 \%$, con elementos emergentes de hasta $27 \mathrm{~m}$, se destacaron Licania sp. (el sasao), Trichilia martiana y Ficus dendrocida (higo-matapalos); los estratos arbolito y arbustivo estuvieron muy diseminados, con alturas promedio de $10 \mathrm{~m}$ y cobertura del $30 \%$, dominados por individuos jóvenes de $A$. butyracea (palma de vino), $B$. guineensis (palma de lata), A. aculeata (palma de corozo) y Nectandra cuspidata (laurel). La vegetación herbácea está muy diseminada con cobertura del 20\%, dominada por Guapira spp. (uvita o cotorrero); las palmas generan a su alrededor en forma de montículos abundante hojarasca y carpetas que pierden regularmente del tronco con cobertura en estos sitios del $80 \%$, pero en general la cobertura de hojarasca es baja en este tipo de hábitat $(<30 \%)$.

Bosque de ribera (BR): Ubicación sitios muestreados dentro de cada hábitat: 1) municipio de Chimichagua, vereda Torrecilla, caño La Calera del Cerro 9 17'49,3' N-73 46' 34,3" $\mathrm{W}$, altitud $65 \mathrm{~m}$; 2) municipio de Chimichagua, vereda Tierra Grata, caño frente a la finca Señor Reyes Mejía 9²1'00,7' N-7347'58,2” $\mathrm{W}$, altitud 56m; 3) municipio de Chimichagua, corregimiento Saloa, finca El Amparo, caño aledaño a la finca $9^{\circ} 09^{\prime} 45,0^{\prime \prime} \mathrm{N}-73^{\circ} 44^{\prime} 14,0^{\prime}$ " $\mathrm{W}$, altitud 46m; 4) municipio de El Paso, corregimiento de Potrerillo, finca El Palomar, 
caño El Palomar 9³3’37,5” N-7340’20,9” W, altitud $40-44 \mathrm{~m}$.

Fisiografía: Bosque caracterizado por especies que crecen a lo largo de caños y corrientes de agua permanentes, donde el elemento predominante en la vegetación no es la palma; con suelo semi-desnudo desde muy húmedo y anegado de consistencia arcillosa, color pardo oscuro, con abundante materia orgánica, hasta suelos bien drenados de consistencia franco-arenosa de color gris pardo y abundante materia orgánica y con más de diez centímetros de profundidad; terreno ondulado, pendientes menores a $10 \%$. El microclima en general es semi-húmedo y la vegetación permanecía casi todo el tiempo con hojas verdes. Hábitat donde se extrae el agua para muchas fincas, bebederos para el ganado, en algunos sitios se veía sometido a extracción de arena para construcción, madera para consumo y entrada de ganado.

Vegetación: Hábitat con seis estratos, donde domina la vegetación de mediano y gran porte con alturas entre 20 hasta los $25 \mathrm{~m}$, la vegetación relictual al borde del curso de agua es dominada por A. butyracea (palma de vino), Inga spp. (guamo) y algunas Apocynaceae. El estrato arbóreo superior tiene una altura promedio de $27 \mathrm{~m}$ y cobertura promedio del $70 \%$, las especies de plantas más comunes son Anacardium excelsum (caracolí) y Brosimum alicastrum (guáimaro); en el estrato arbóreo inferior con una altura promedio de $14 \mathrm{~m}$ y cobertura promedio del $80 \%$, los elementos dominante son Matayba macrostylis, Protium heptaphyllum, Xylopia aromatica e Himatanthus articulates que en general ocupan todas las orillas de los sistemas lóticos que corren y se forman en la región, presenta elementos emergentes correspondientes a Schefflera morototoni (alcanza 18m); en el estrato arbolito se destacan Tabebuia rosea (roble) y Amaioua corymbosa, con alturas que alcanzan los $12 \mathrm{~m}$ y cobertura promedio del $80 \%$; en el sotobosque los estrato arbustivo y herbáceo son abiertos con cobertura del 50\% ambos, altura entre 3-5m y dominados por Psychotria officinali; el estrato rasante es dominado por Phaseolus caracola y Albizia niopoides y cobertura promedio $<50 \%$, en la base de árboles grandes se encuentra abundante hojarasca, sin embargo junto a los lechos de los caños es removida constantemente en periodos de lluvia al subir la cota de inundación.

Sabana arbolada (SA): Ubicación de los sitios muestreados dentro de cada hábitat: 1) municipio de Chimichagua, vereda Tierra Grata, finca Villa Hermosa 9'21'13,2" $\mathrm{N}-73^{\circ} 48^{\prime} 05,9^{\prime \prime} \mathrm{W}$, altura 55m; 2) municipio de El Paso, corregimiento de Potrerillo, 9³2'44,5", N-73³9'11,4" W, altura 55m; 3) municipio de El Paso, corregimiento La Loma, finca La Pachita, sitio ciénaga La Pachita 9³8'9,5" N-73³6'59,2" W, altura 50m.

Fisiografía: El término sabana se refiere aquí, al tipo de formación vegetal dominada por pastos naturales y sembrados, también por herbáceas y rasantes con manchas muy pequeñas de arboles dispersos en esta matriz. Son pastizales de suelo desnudo de composición franco-arcillosa, escasa materia orgánica, con menos de diez centímetros de profundidad y poca a nula cobertura de hojarasca; terreno ondulado, pendientes menores a $10 \%$. El microclima en general es muy seco y la vegetación en la estación seca permanece reseca y en época de lluvias reverdece por un breve periodo. Hábitat expuesto a constante quema y ganadería extensiva e intensiva, generalmente dentro de éste se encuentran pozos temporales y jagüeyes con algo de vegetación herbácea a los bordes, donde el ganado bebe y se refresca.

Vegetación: Hábitat con cuatro estratos, donde dominan los estratos herbáceo y rasante con matorrales bajos y pastos naturales y/o sembrados. En el estrato arbolito hay algunos árboles dispersos de mediano porte como $S$. saman (campano), Cresentia cujete (totumo), Psidum sp. (guayabo), A. butyracea (palma de vino) y Gliricidia sepium (matarratón), los cuales constituyen las cercas vivas y remanentes pequeños de vegetación con portes de 
3-8m que se dejan para sombra del ganado y complemento de la alimentación de los mismos y cobertura del 20\%; en el estrato arbustivo con coberturas del $30 \%$, se encuentran individuos jóvenes de $A$. butyracea (palma de vino) y A. aculeata (corozo) mezclados con matorral y vegetación espinosa como Opuntia caracasana (pencas), Pilosocereus lanuginosus y Cereus exagonus (cardón), Aechmea magdalenae (piñuela); el estrato herbáceo y rasante la cobertura promedio es del $60 \%$ para ambos y están conformados principalmente por Andropogon fastigiatus (pasto rabo de zorro), Menlinis minutiflora (pasto gordura), Mimosa pigra (matas bajas de dormidera) y en los bordes de ciénaga se encuentran Coccoloba costata y Matayba camptoneura. En la base de árboles grandes se genera abundante hojarasca, sin embargo es muy baja en todo el terreno con cobertura menor al $20 \%$.

Muestreo: Se efectuaron cuatro salidas de 10 días efectivos de muestreo cada una (réplicas temporales), por dos investigadores, en los cinco hábitats (dos días por sitio en cada hábitat ya definidos en cada salida-réplica espacial), en noviembre de 2006 y octubre de 2007 (época de lluvias) y enero y julio de 2007 (época seca); se buscó abarcar equitativamente el periodo seco (dos salidas) y el periodo de lluvias (dos salidas). Para un total de 40 días de muestreo efectivo.

Hábitat: Para desarrollar las comparaciones, se definieron los cinco hábitats básicos previamente descritos, se muestrearon en cada salida dos sitios (unidad de muestreo), separados espacialmente que representaban cada hábitat.

Reptiles: Mediante un diseño aleatorio de caminatas, se realizaron búsquedas por encuentro visual cronometradas (Crump \& Scott 1994), es decir un muestreo aleatorio estratificado por hábitats; se efectuaron diariamente recorridos de $400 \mathrm{~m}$ en el día y $400 \mathrm{~m}$ en la noche en el mismo sitio, con el fin de observar y/o capturar la mayor cantidad de individuos, identificarlos con la utilización de claves especializadas (Peters \& Donoso-Barros 1970, Peters \& Orejas-Miranda 1970, PérezSantos \& Moreno 1986, 1988, Bernal-Carlo 1991, Páez et al. 2002, Campbell \& Lamar 2004, Ayala \& Castro: documento inédito, Lagartos de Colombia/Lizards of Colombia. Volumen I-V. Colombia. 820 pp.) y liberarlos; la captura de los individuos fue manual y/o con gancho, y se exploraron a un metro de cada lado dentro de los potenciales microhábitat donde se podían encontrar los reptiles.

Cada hábitat fue recorrido por dos investigadores durante ocho horas efectivas en el cual se realizaban búsquedas libres (cuatro horas en el día 09:00-13:00 y cuatro horas en la noche 18:00-22:00), para un esfuerzo diario de $16 \mathrm{~h} /$ hombre de trabajo, $128 \mathrm{~h} /$ hombre para cada hábitat y un total de $640 \mathrm{~h} /$ hombre durante todo el estudio.

La ventaja de este diseño y método es que permiten el cubrimiento de todos los hábitats establecidos y la obtención de una lista de especies con su abundancia relativa (frecuencia de aparición) sin violar los supuestos de aleatoriedad de muestreo, necesario para hacer comparaciones entre áreas con y sin vegetación cerrada (Heyer et al. 1994, Angulo et al. 2006).

Análisis estadístico: Con el fin de tener una aproximación del número de especies que se puede encontrar en el complejo cenagoso de Zapatosa, se construyó la curva de acumulación de especies (Colwell \& Coddington 1994), a partir de los estimadores de riqueza no paramétricos Jacknife 1, Jacknife 2 y Bootstrap, usados cuando no se asume homogeneidad ambiental en las muestras (distintos hábitats) (Magurran 1989, 2004). Con los valores máximos calculados de riqueza, se determinó el porcentaje de representatividad del estudio (Soberón \& Llorente 1993). Todos los estimadores se corrieron con 999 permutaciones, se calcularon las especies raras: únicas (singletons) y duplicadas (doubletons), para determinar si se redujeron a medida que el muestreo avanzó; estas pruebas se realizaron mediante el programa EstimateS Win 7.5.0 (Colwell 2005). 
Para cada hábitat se realizaron curvas de acumulación de especies, con el próposito de establecer el número de especies en cada hábitat, entonces se utilizaron los estimadores no paramétricos ICE y Chao 2, eficientes para estimar la riqueza de especies con datos de presencia-ausencia en muestras que provienen del mismo tipo de hábitat y el estimador Bootstrap que arroja resultados precisos al estimar la riqueza de comunidades con numerosas especies raras (Moreno 2001). También se calcularon la representatividad de los muestreos y los valores de las especies raras por hábitat para determinar si disminuyeron al aumentar el esfuerzo de muestreo.

Por lo tanto se calculó la diversidad alfa, como la riqueza o número total de especies encontradas en cada uno de los cinco hábitats establecidos, dentro del complejo ciénaga de Zapatosa, al igual que se estimó la riqueza específica, mediante el índice de diversidad de Margalef, el cual presupone una relación funcional entre el número de especies y el número total de individuos del sitio. Se calculó la equitatividad, a partir de la función de Shannon-Wiener que expresa la uniformidad de los valores de importancia a través de todas las especies de la muestra (Moreno 2001) y cuenta con la ventaja de ser independiente respecto al tamaño de la misma, ya que a partir de un muestreo al azar se estima la equidad de una comunidad con base en una muestra que presumiblemente contiene todas las especies (Hair 1987). Los resultados obtenidos para el índice Shannon-Wiener dentro de los hábitats se contrastaron entre sí con un análisis de varianza (Magurran 1989, 2004), para determinar si las diferencias numéricas son o no significativas, además se realizó una comparación a posteriori, prueba pareada de Tukey; para identificar si existe alguna fuente de variación en la heterogeneidad entre hábitats y posteriormente explicar las posibles causas biológicas.

Para analizar si en general y en cada hábitat, con un número estandarizado de individuos la riqueza se mantiene por los grupos taxonómicos serpientes y saurios, que resultaron ser los más abundantes y mejor representados dentro del estudio; se realizaron curvas de acumulación de especies usando el método de rarefacción por muestras acumuladas (Gotelli \& Colwell 2001); para estos cálculos se utilizó el programa PAST 1.90 (Hammer et al. 2001).

Por consiguiente se comparó la composición, abundancia y la uniformidad de especies entre hábitats y al utilizar curvas representativas de diversidad-dominancia (May 1975, Feinsinger 2001, Gardner et al. 2007) se compararon con una prueba de KolmogorovSmirnov (Zar 1998, Magurran 2004); para identificar si los parámetros descriptores que muestran las gráficas son diferentes entre los hábitats. Se utilizó el programa PAST 1.90 (Hammer et al. 2001).

Para detectar las diferencias en la estructura de las comunidades por hábitat se realizó un análisis de similitud de una vía (ANOSIM), prueba no paramétrica entre dos o más grupos, basada en una medida de distancia la cual parte de una matriz de similitud (en este caso BrayCurtis) (Clarke 1993), en la que se calcula inicialmente a partir de la matriz de abundancias por hábitat; la prueba permite comparar entre pares de hábitats. Para contrastar los grupos que causan la diferencia se utilizó una prueba corregida de Bonferroni (análoga a las pruebas a posteriori del análisis de varianza); para todo esto se usó el programa PAST 1.90 (Hammer et al. 2001).

Asimismo, se estimó la proporción que aporta cada especie de reptil a la diferencia entre hábitats, determinada por el porcentaje de disimilitud entre ellas mediante la subrutina SIMPER del programa estadístico PRIMER versión 5 (Clarke \& Gorley 2001)

Después, se calculó diversidad beta mediante la complementariedad de especies entre pares de hábitats. La complementariedad hace referencia al grado de disimilitud en la composición de especies entre pares de biotas (Colwell \& Coddington 1994); la variación oscila entre cero y uno; a medida que aumenta este valor también aumenta la diferencia entre pares de biotas. De igual forma, se calculó el porcentaje de complementariedad entre hábitats a partir del número de especies compartidas 
sobre el número total de especies entre hábitats por cien (Moreno 2001, Magurran 2004).

Adicionalmente, se realizó una comparación nominal y porcentual de la lista de las especies de reptiles registradas en este trabajo frente a los inventarios de otros estudios: síntesis del Cesar, franja tropical de la serranía de Perijá, Cesar (Moreno-Arias et al . 2009); humedales de Córdoba (Castaño-Mora et al. 2004a, Carvajal-Cogollo 2006, Cárdenas-Arévalo et al. 2010), el bosque seco del santuario de vida silvestre de Los Besotes (Rueda-Almonacid et al. 2008), bosques relictuales de Córdoba (Carvajal-Cogollo \& Urbina-Cardona 2008), la Jagua de Ibirico-Serranía de Perijá (HernándezRuz et al. 2001, Castaño-Mora et al. 1997) y por último con revisión de bibliografía (Ayala 1986, Pérez-Santos \& Moreno 1986, 1988, Bernal-Carlo 1991, Castaño-Mora 1992, Sánchez-C et al. 1995, Rengifo \& Lundberg 1999, Ceballos-Fonseca 2000, Campbell \& Lamar 2004, Carvajal-Cogollo 2006, Ayala \& Castro: documento inédito, Lagartos de Colombia/ Lizards of Colombia. Volumen I-V. Colombia. 820 pp.), con el fin de establecer nuevos registros al igual que datos de ampliaciones de distribución en la zona y de esta forma hacer una comparación con lo que se conoce para la región Caribe y para todo el país.

En la descripción general del complejo cenagoso de Zapatosa y en la comparación de listas, se incluyeron siete especies de reptiles, que no se utilizaron en los análisis de diversidad por hábitat y en las curvas de acumulación de especies, por lo siguiente: Bachia bicolor e Imantodes gemmistratus fueron encontradas solamente en el pre-muestreo, Hemidactylus frenatus es una especie casi exclusiva de edificaciones o áreas urbanizadas, Rhinoclemmys melanosterna y Podocnemys lewyana fueron encontradas en fincas donde son mantenidas como mascotas o para consumo, para Crocodylus acutus se registró el uso de sus restos como piel y cráneo y de Mesoclemmys dahli se contaba con fotografías aunque posteriormente en una salida adicional se corroboró su presencia en la zona (Medina-Rangel \& ForeroMedina 2008).

\section{RESULTADOS}

Riqueza total: En todo el estudio se registraron 857 individuos de la clase Reptilia distribuidos en 48 especies y 18 familias (Cuadro 1). En el orden Squamata se encontraron 40 especies, distribuidas en 20 de lagartos de ocho familias: Corytophanidae, Iguanidae, Gekkonidae, Gymnophthalmidae, Polychrotidae, Teiidae, Tropiduridae y Scincidae; y 20 de serpientes de tres familias: Boidae, Colubridae y Viperidae; el orden Testudinata con seis especies de tortugas distribuidas en seis familias: Chelidae, Emydidae, Geoemydidae, Kinosternidae, Podocnemididae y Testudinidae; y el orden Crocodylia con dos especies de la familia Crocodylidae (Apéndice 1).

\author{
CUADRO 1 \\ Número de taxones de reptiles registrados \\ en el área de estudio
}

TABLE 1

Number of taxa of reptiles recorded in the study area

\begin{tabular}{lcc}
\multicolumn{1}{c}{ ORDEN } & No Familias & No Especies \\
Squamata & 11 & 40 \\
Testudinata & 6 & 6 \\
Crocodylia & 1 & 2
\end{tabular}

Para los saurios, las familias con mayor número de especies fueron Gekkonidae con cinco y Gymnophthalmidae y Teiidae con cuatro cada uno (Apéndice 1). El mayor número de individuos lo presentaron Gonatodes albogularis (141), Anolis tropidogaster (126), Anolis auratus (105) y Cnemidophorus lemniscatus (70). Para las serpientes, la familia con más especies fue Colubridae con 14 (Fig. 3 ), de éstas presentaron el más alto número de individuos Leptodeira septentrionalis (21), Thamnodynastes gambotensis (16) e Imantodes cenchoa (10) (Apéndice 2). Los géneros de reptiles que presentaron el mayor número de especies fueron Anolis (Polychrotidae) y Amei$v a$ (Teiidae) cada uno con dos. 


\section{Estimación de la riqueza general}

Según los estimadores de riqueza Bootstrap, Jacknife uno y dos, la representatividad del muestreo osciló entre $85 \%$ y el $93 \%$ de las especies esperadas para el estudio (Apéndice 3), el número de especies observadas no se estabiliza si se le compara con las curvas Jacknife uno y dos, pero se asemeja al comportamiento de Bootstrap (Fig. 1). En la medida en que avanzó el muestreo, las especies únicas, mostraron una clara reducción en número, mientras que la disminución fue leve para el número de especies duplicadas, lo cual prueba una aceptable eficiencia del muestreo en toda la zona (Fig. 1).

Para el área de estudio, la riqueza de lagartos fue igual a la de serpientes, pero para este último grupo y para las tortugas, las curvas no alcanzaron la asíntota (Fig. 2). Los estimadores de riqueza Bootstrap, Jacknife uno y dos calculados para los grupos taxonómicos mejor representados, muestran que la representatividad del muestreo para los saurios osciló entre el $95 \%$ y el $97 \%$ de las especies esperadas para la zona de estudio y a medida que se avanzó en el muestreo las especies únicas y las duplicadas mostraron una reducción en número (Apéndice 3); mientras para las serpientes, la representatividad que se encontró fluctúo entre el $81 \%$ y $89 \%$, las especies únicas se reducen, mientras las duplicadas aumentaron (Apéndice 3). Las tortugas y los cocodrilos están pobremente representados en el muestreo, por lo cual es difícil estimar su porcentaje de representatividad, seguramente el muestreo más enfocado en ambientes terrestres influyó en lo bajo de este resultado.

\section{Diversidad por hábitats: diversidad alfa}

El hábitat que registró la mayor proporción de especies (89\%) fue el bosque de ribera (Cuadro 2), seguido por el palmar con el $61 \%$ de las especies, el bosque seco con igual porcentaje $(61 \%)$, la sabana arbolada con 56\%, mientras el bosque casmófito presentó la menor proporción (41\%). En cuanto al número de individuos, el bosque de ribera mostró también el mayor porcentaje $(25 \%)$, seguido por el bosque seco con el $22 \%$, el palmar con el $21 \%$, el bosque casmófito con el $17 \%$, mientras que en la sabana arbolada se registra la menor cantidad de individuos (15\%) (Cuadro 2).

La riqueza específica de los hábitats (índice de Margalef), siguió una tendencia similar a la proporción de especies, donde el bosque de ribera presentó el mayor valor, seguido por

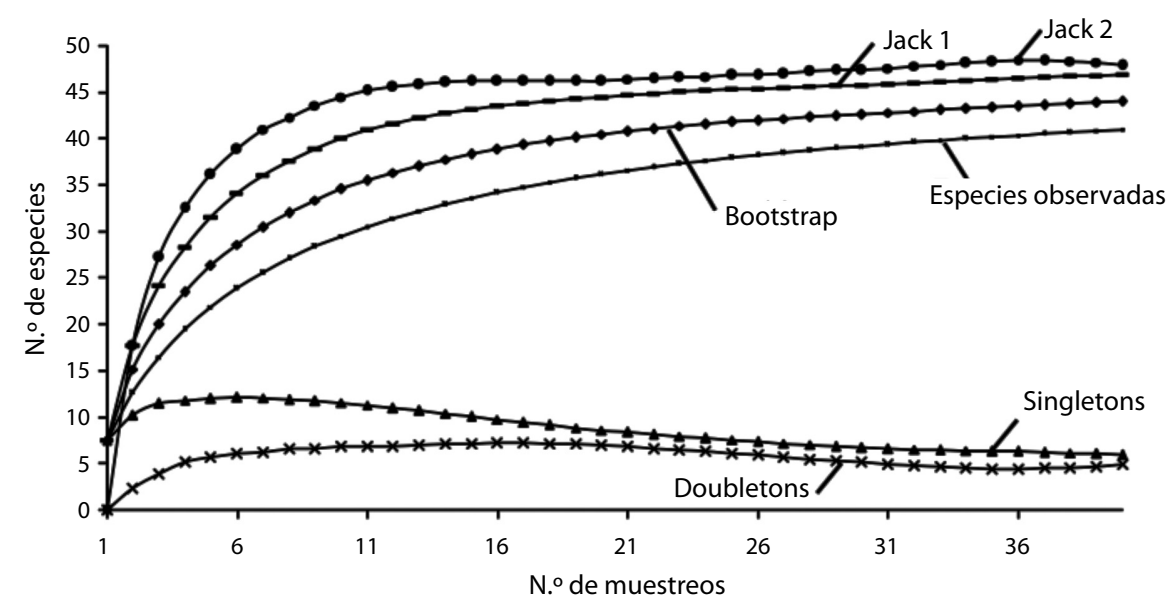

Fig. 1. Curvas de acumulación de especies de reptiles durante el periodo de estudio para toda la zona de estudio. Fig. 1. Species accumulation curves of reptiles during the study period for all study area. 


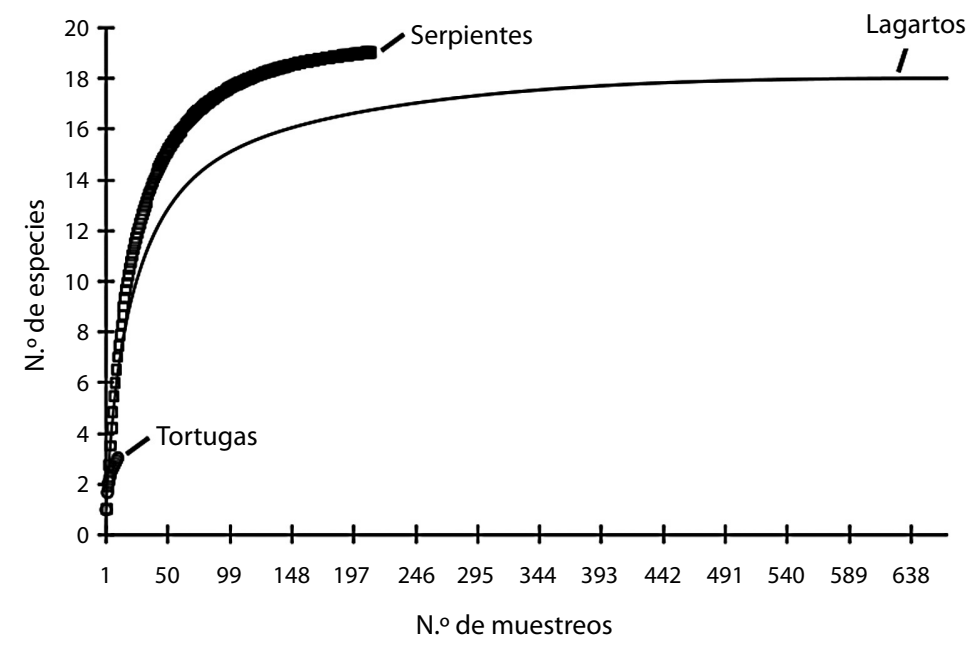

Fig. 2. Curvas de rarefacción para acumulación de las especies de reptiles por grupos (serpientes, lagartos y tortugas) en todos los hábitats muestreados durante el periodo de estudio en el complejo cenagoso de Zapatosa.

Fig. 2. Rarefaction curves for accumulation of the reptile species groups (snakes, lizards and turtles) in all the habitats sampled through the study period in the Zapatosa's wetland complex.

\section{CUADRO 2}

Especies, individuos e índices de diversidad de reptiles registrados en cada uno de los hábitats.

(BP: Bosque casmófito, BS: Bosque seco, P: Palmar, BR: Bosque de ribera y SA: Sabana arbolada).

\section{TABLE 2}

Species, individuals and diversity indices of reptiles recorded in each one of the habitats.

(BP: chasmophyte forest, BS: dry forest, P: palm-grove, BR: riparian forest and SA: tree-lined savanna).

$\begin{array}{lcccccc} & \text { TOTAL* } & \text { BP } & \text { BS } & \text { P } & \text { BR } & \text { SA } \\ \text { No de especies } & 41 & 17 & 25 & 26 & 34 & 23 \\ \text { No de individuos } & 812 & 136 & 183 & 171 & 196 & 126 \\ \text { Margalef } & --- & 3.257 & 4.607 & 4.862 & 6.252 & 4.549 \\ \text { Shannon-Wiener H } & --- & 2.156 & 2.672 & 2.575 & 2.888 & 2.542 \\ \text { Uniformidad (H/lnS) } & --- & 0.761 & 0.830 & 0.790 & 0.819 & 0.811\end{array}$

*TOTAL: se excluyeron las siete especies y 45 individuos mencionados. / * TOTAL: seven species and 45 individuals were excluded mentioned

el palmar, el bosque seco, la sabana arbolada y finalmente el bosque casmófito (Cuadro 2). La equidad entre hábitats medida con el índice de Shannon-Wiener mostró un valor más alto en el bosque de ribera y en el bosque seco frente a los demás hábitats, sin embargo, no hubo diferencias estadísticamente significativa entre la heterogeneidad de los hábitats $\left(\mathrm{F}_{(4,200), 0.05}=0.245, \mathrm{p}=0.913\right)$.

\section{Número de especies por familia en cada hábitat}

En los cinco hábitats, la familia con el mayor número de especies fue Colubridae 
(Fig. 3). Teiidae alcanzó un valor representativo de especies en el palmar, bosque de ribera y en la sabana arbolada, mientras Gekkonidae adquirió un número de especies alto en el bosque de ribera y el bosque casmófito (Fig. 3).

\section{Número de individuos por familia en cada hábitat}

Para cuatro de los cinco hábitats, las familias con el mayor número de individuos fueron Polychrotidae y Gekkonidae, tendencia que cambia en la sabana arbolada, donde
Teiidae presenta el mayor número de individuos (Fig. 4). Colubridae que es la familia más rica en especies, solamente alcanza un número significativo de individuos en el bosque de ribera y en el bosque seco (Apéndice 1 y 2).

Según los estimadores de riqueza calculados para cada uno de los hábitats, la representatividad del muestreo osciló entre el $66 \%$ y el $90 \%$ de las especies esperadas para cada hábitat (Cuadro 3). Las especies raras (únicas y duplicadas) no muestran una reducción en número a lo largo del estudio (Apéndice 3).
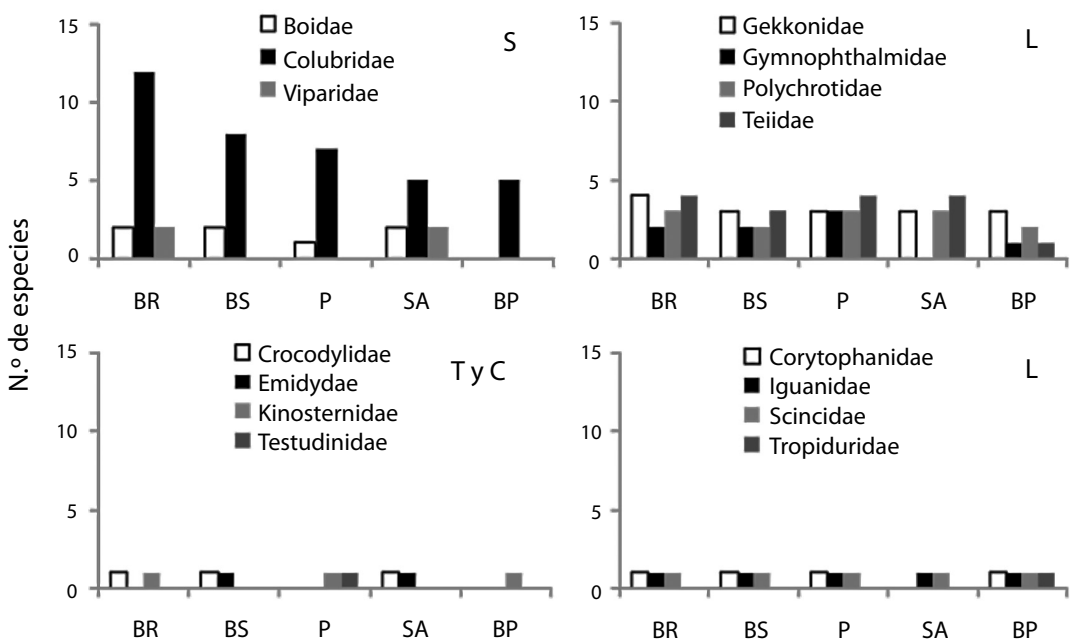

Fig. 3. Número de especies por familia de reptiles en los hábitats muestreados. (BP: Bosque casmófito, BS: Bosque seco, P: Palmar, BR: Bosque de ribera, SA: Sabana arbolada). (S) Serpientes, (L) Lagartos, (T y C) Tortugas y cocodrilos.

Fig. 3. Number of species by family of reptiles in the habitats sampled. (BP: chasmophyte forest, BS: dry forest, P: palmgrove, BR: riparian forest and SA: tree-lined savanna). (S) Snakes, (L) Lizards, (T y C) turtles and crocodiles.

CUADRO 3

Estimadores de riqueza no paramétricos para la riqueza esperada y representatividad del muestreo de los hábitats. (BP: Bosque casmófito, BS: Bosque seco, P: Palmar, BR: Bosque de ribera y SA: Sabana arbolada)

TABLE 3

Nonparametric richness' estimators for the expected richness and completeness of the sampling of habitats. (BP: chasmophyte forest, BS: dry forest, P: palm-grove, BR: riparian forest and SA: tree-lined savanna)

$\begin{array}{llcccccc} & & \text { BP } & \text { BS } & \text { P } & \text { BR } & \text { SA } \\ \text { Especies observadas } & & 17 & 25 & 26 & 34 & 23 & 29.44 \\ \text { Especies esperadas } & \text { ICE } & 21.98 & 31.24 & 39.1 & 45.05 & 25.45 \\ & \text { Chao 2 } & 20.28 & 28.06 & 34.64 & 42.53 & 26.74 \\ \text { Representatividad } & & 19.42 & 28.55 & 30.54 & 39.39 & 78-90 \%\end{array}$




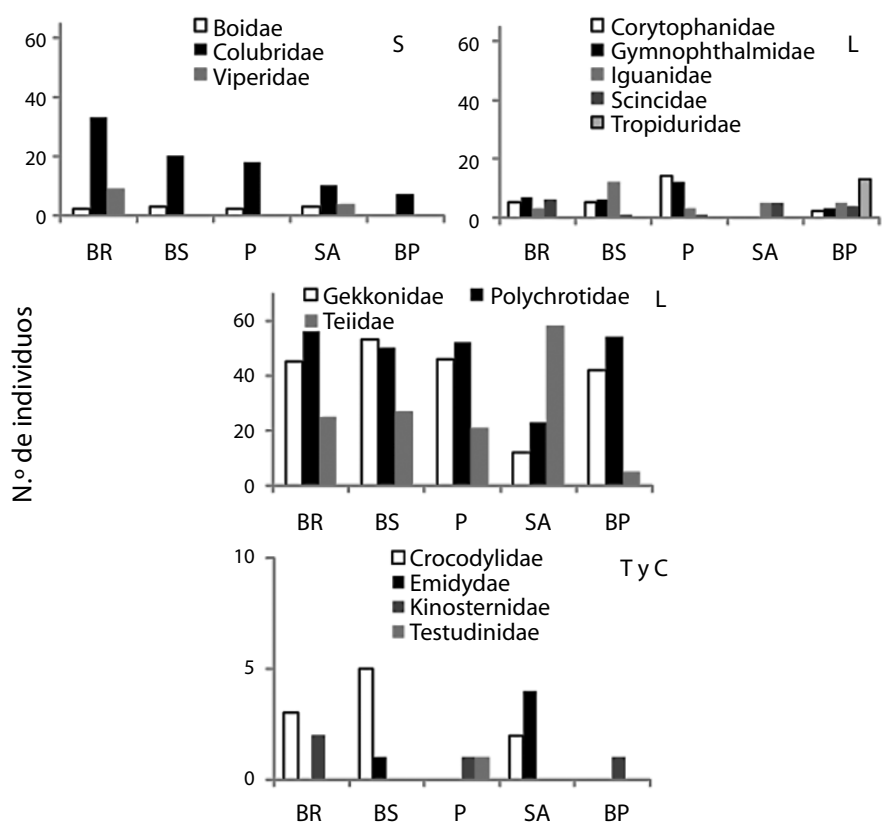

Fig. 4. Número de individuos por familia de reptiles en los hábitats muestreados. (BP: Bosque casmófito, BS: Bosque seco, P: Palmar, BR: Bosque de ribera, SA: sabana arbolada). (S) Serpientes, (L) Lagartos, (T y C) Tortugas y cocodrilos.

Fig. 4. Number of individuals by family of reptiles in the habitats sampled. (BP: chasmophyte forest, BS: dry forest, P: palmgrove, BR: riparian forest and SA: tree-lined savanna). (S) Snakes, (L) Lizards, (T y C) turtles and crocodiles.

En los diferentes hábitats analizados, la curva de la riqueza de los reptiles no alcanzó la asíntota (Fig. 5). Al estandarizar la muestra a un número igual de individuos $(\mathrm{n}=126)$, la tendencia en la jerarquía de riqueza de especies, representadas por la comparación de los diferentes hábitats, se mantiene para el bosque de ribera y bosque casmófito; sin embargo el bosque seco, el palmar y la sabana arbolada serían igual de ricos en especies si se hubiese encontrado la misma cantidad de individuos (Fig. 5).

\section{Estimadores de la riqueza de especies}

Al observar la curva para los grupos taxonómicos mejor representados (saurios y serpientes), se ve que la curva de acumulación de especies para los saurios se estabilizó en casi todos los hábitats (Fig. 6). Sin embargo, para las serpientes no pasó lo mismo (Fig. 7), para este último grupo la representatividad

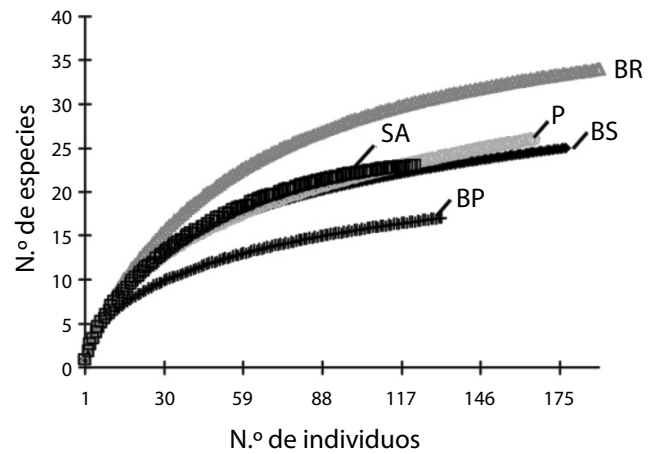

Fig. 5. Curvas de rarefacción para acumulación de especies de reptiles para los hábitats muestreados. (BP: Bosque casmófito, BS: Bosque seco, P: Palmar, BR: Bosque de ribera y SA: Sabana arbolada). La amplitud de los símbolos es equivalente a la amplitud del intervalo de confianza.

Fig. 5. Rarefaction curves for accumulation of reptile species for the habitats sampled. (BP: chasmophyte forest, BS: dry forest, P: palm-grove, BR: riparian forest and SA: tree-lined savanna). The amplitude of the symbols is equivalent to the width of confidence interval. 


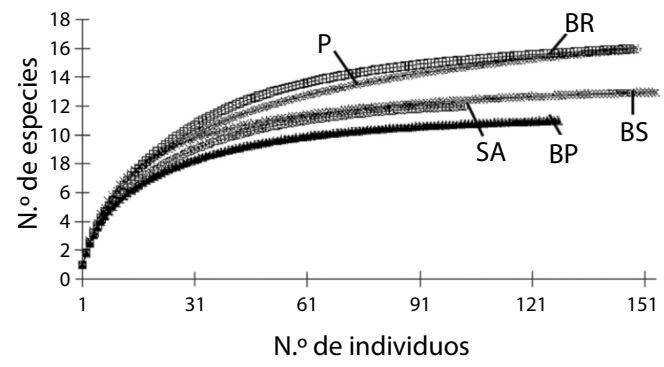

Fig. 6. Curvas de rarefacción para acumulación de lagartos para los hábitats muestreados. (BP: Bosque casmófito, BS: Bosque seco, P: Palmar, BR: Bosque de ribera y SA: Sabana arbolada). La amplitud de los símbolos es equivalente a la amplitud del intervalo de confianza.

Fig. 6. Rarefaction curves for accumulation of lizards species for the habitats sampled. (BP: chasmophyte forest, BS: dry forest, P: palm-grove, BR: riparian forest and SA: tree-lined savanna). The amplitude of the symbols is equivalent to the width of confidence interval.

fue más baja en comparación con los saurios (Apéndice 3).

$\mathrm{Al}$ estandarizar la muestra con un número igual de individuos $\left(\mathrm{n}_{\text {lag }}=103, \mathrm{n}_{\text {serp }}=17\right)$, la tendencia en la jerarquía de riqueza de especies de saurios entre los diferentes hábitats se conservó al igual que la tendencia general (Fig. 6), mientras que para las serpientes la disposición cambió, al presentar igual riqueza en todos los hábitat en el punto donde se encuentra el menor número de individuos (Fig. 7).

\section{Curvas diversidad-dominancia}

Los hábitats exhibieron una alta uniformidad (Cuadro 2), reflejada en las curvas de diversidad-dominancia, con pendientes similares, poco pronunciadas para cada hábitat (Fig. 8). Cuando se compararon las curvas entre los hábitats, resultaron diferencias estadísticamente significativas entre los patrones de distribución de abundancia de especies dominantes y raras entre el bosque de ribera frente a las sabanas arboladas $(\mathrm{D}=0.429, \mathrm{p}=0.009)$.

Las especies que dominaron el ensamble fueron Gonatodes albogularis, Anolis tropidogaster y Anolis auratus que se mantuvieron

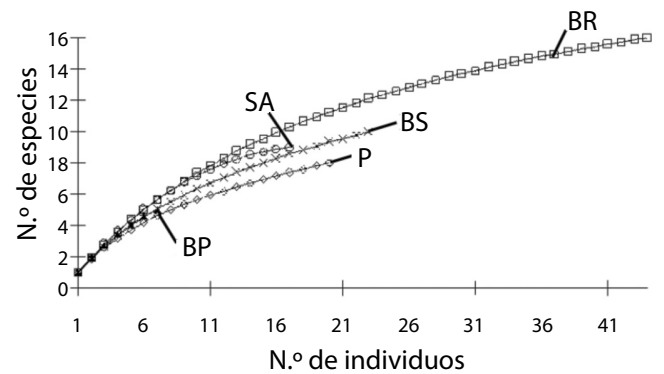

Fig. 7. Curvas de rarefacción para acumulación de serpientes para los hábitats muestreados. (BP: Bosque casmófito, BS: Bosque seco, P: Palmar, BR: Bosque de ribera y SA: Sabana arbolada). La amplitud de los símbolos es equivalente a la amplitud del intervalo de confianza.

Fig. 7. Rarefaction curves for accumulation of snakes species for the habitats sampled. (BP: chasmophyte forest, BS: dry forest, P: palm-grove, BR: riparian forest and SA: tree-lined savanna). The amplitude of the symbols is equivalent to the width of confidence interval.

en las posiciones jerárquicas más altas en casi todos los hábitats (Fig. 8), sin embargo, en la sabana arbolada Cnemidophorus lemniscatus, Ameiva ameiva y Anolis auratus pasaron a ser las especies dominantes del ensamble (Fig. 8). Casi el $70 \%$ de las especies raras fueron serpientes, como Liophis lineatus que apareció en casi todos los hábitats, pero con uno o dos individuos, entre tanto, otras especies como Leptodeira septentrionalis fueron elementos comunes con abundancias intermedias en todos los hábitats (Fig. 8). Con respecto al total de especies encontadas en cada hábitat, el bosque casmófito presentó la mayor proporción de especies dominantes en abundancia en el ensamble, mientras el bosque de ribera la más baja (Fig. 8), además el bosque de ribera mostró una mayor proporción de especies raras.

\section{Composición de especies}

La estructura y composición de especies de reptiles entre los tipos de hábitat fue estadísticamente diferente (ANOSIM, R=0.1093, $\mathrm{p}=0.0109)$, la sabana arbolada resultó ser el hábitat que más influyó en que la diferencia global fuera significativa (Valores del test de 


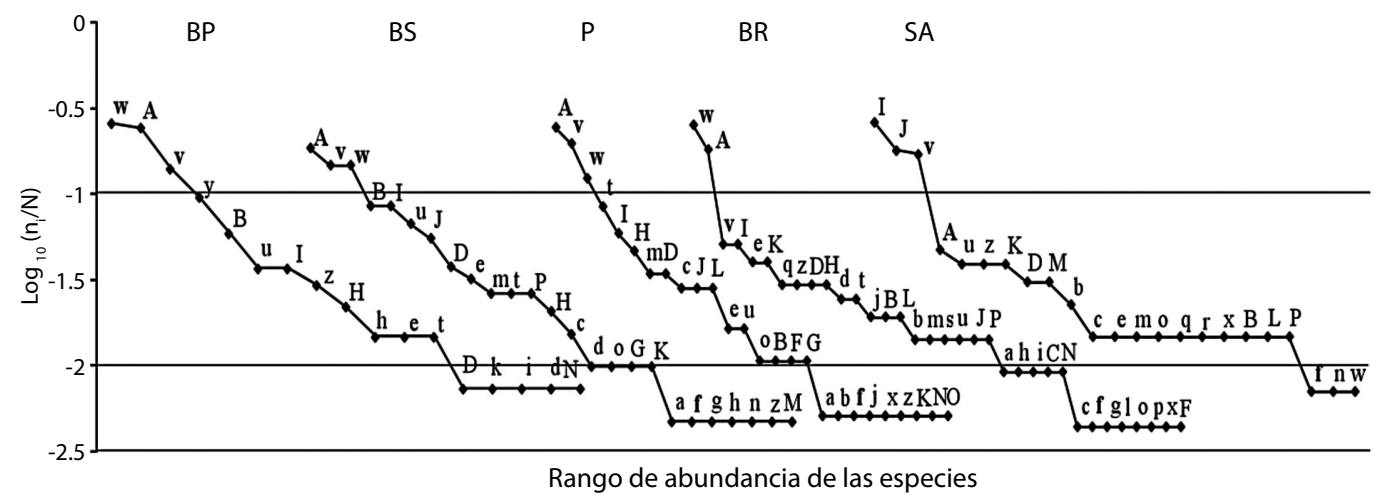

Fig. 8. Curvas de rango abundancia para los reptiles en cinco tipos de hábitat alrededor del complejo cenagoso de Zapatosa en el departamento del Cesar (Colombia). (BP: Bosque casmófito, BS: Bosque seco, P: Palmar, BR: Bosque de ribera, y SA: Sabana arbolada). Chironius carinatus (a), Helicops danieli (b), Imantodes cenchoa (c), Leptophis ahaetulla (d), Leptodeira septentrionalis (e), Liophis lineatus (f), Mastigodryas pleei (g), Oxybelis aeneus (h), Phimophis guianensis (i), Pseudoboa neuwiedii (j), Spillotes pullatus (k), Enulius flavitorques (1), Thamnodynastes gambotensis (m), Boa constrictor (n), Corallus ruschenbergerii (o), Epicrates cechria (p), Bothrops asper (q), Crotalus durissus (r), Porthidium lansbergii (s), Basiliscus basiliscus (t), Iguana iguana (u), Anolis auratus (v), Anolis tropidogaster (w), Polychrus marmoratus (x), Stenocercus erythrogaster (y), Mabuya sp. (z), Gonatodes albogularis (A), Lepidoblepharis sanctaemartae (B), Sphaerodactylus heliconiae (C), Thecadactylus rapicaudus (D), Gymnophthalmus speciosus (F), Leposoma rugiceps (G), Tretioscincus bifasciatus $(\mathrm{H})$, Cnemidophorus lemniscatus $(\mathrm{I})$, Ameiva ameiva $(\mathrm{J})$, Ameiva festiva $(\mathrm{K})$, Tupinambis teguixin $(\mathrm{L})$, Trachemys callirostris $(\mathrm{M})$, Kinosternon scorpioides $(\mathrm{N})$, Chelonoidis carbonaria $(\mathrm{O})$, Caiman crocodilus $(\mathrm{P})$. Especies que mantienen en todos o casi los hábitats sus valores de dominancia. En negrilla: Gonatodes albogularis (A), Anolis tropidogaster (w), Anolis auratus (v), Liophis lineatus (f).

Fig. 8. Rank abundance curves for reptiles in five types of the habitat around the Zapatosa's wetland complex in the departmento del Cesar (Colombia). (BP: chasmophyte forest, BS: dry forest, P: palm-grove, BR: riparian forest and SA: tree-lined savanna).

corrección de Bonferroni: SA-BS: $\mathrm{R}=0.3376$, $\mathrm{p}=0.0028$; SA-P: $\mathrm{R}=0.341, \mathrm{p}=0.0018$; SA-BR: $\mathrm{R}=0.24, \mathrm{p}=0.0111$ ).

La mayor disimilitud entre hábitats en cuanto a la abundancia y composición de las especies se presentó entre el bosque casmófito y la sabana arbolada con un $66 \%$ y las especies que más contribuyeron a esto fueron Anolis tropidogaster (SIMPER 20\%) y Gonatodes albogularis (SIMPER 17\%); el bosque de ribera y la sabana arbolada también presentaron una alta disimilitud con $60 \%$, donde igualmente Anolis tropidogaster (SIMPER 24\%) y Gonatode albogularis (SIMPER 15\%) favorecieron esta diferencia. En general, estas especies son las que aportaron la mayor proporción de diferencia entre los hábitats, solamente en el bosque casmófito Stenocercus erythrogaster contribuyó con un porcentaje más alto de disimilitud (SIMPER 19\%).

\section{Recambio de especies entre hábitats: diversidad beta}

El bosque de ribera presentó el mayor número de especies exclusivas con cuatro, seguido del bosque casmófito con dos, el palmar y la sabana arbolada con una cada uno y finalmente el bosque seco no mostró especies exclusivas (Apéndice 2).

El palmar y el bosque de ribera presentaron la más alta similitud, debido a la cantidad de especies en común (Cuadro 4). El bosque seco y el bosque de ribera compartieron un número alto de especies, pero proporcionalmente el bosque seco y la sabana arbolada son 
CUADRO 4

Valores porcentuales de especies compartidas y complementariedad de especies entre pares de hábitats. (BP: Bosque casmófito, BS: Bosque seco, P: Palmar, BR: Bosque de ribera y SA: Sabana arbolada)

TABLE 4

Percentage values of shared species and complementarity of species between pairs of habitats. (BP: chasmophyte forest, BS: dry forest, P: palm-grove, BR: riparian forest and SA: tree-lined savanna)

$\begin{array}{lcccccccccc} & \text { BP-BS } & \text { BP-P } & \text { BP-BR } & \text { BP-SA } & \text { BS-P } & \text { BS-BR } & \text { BS-SA } & \text { P-BR } & \text { P-SA } & \text { BR-SA } \\ \text { No sp compartidas } & 13 & 12 & 14 & 9 & 19 & 22 & 18 & 24 & 18 & 20 \\ \text { No sp total entre par de hábitats } & 29 & 31 & 37 & 31 & 32 & 37 & 30 & 36 & 31 & 37 \\ \text { Porcentaje similitud } & 44.83 & 38.71 & 37.84 & 29.03 & 59.38 & 59.46 & 60.00 & 66.67 & 58.06 & 54.05 \\ \text { Complementariedad entre áreas } & & & & & & & & & & \\ \text { Únicas } & 16 & 19 & 23 & 22 & 13 & 15 & 12 & 12 & 13 & 17 \\ \text { Complementariedad } & 0.55 & 0.61 & 0.62 & 0.71 & 0.41 & 0.41 & 0.40 & 0.33 & 0.42 & 0.46\end{array}$

los que exhibieron el segundo porcentaje más alto de especie compartidas; mientras que el bosque casmófito y la sabana arbolada tienen la más baja proporción de especies en común (Cuadro 4). En conjunto, el par de hábitats que tuvieron el mayor número de especies únicas son el bosque casmófito y el bosque de ribera, al mismo tiempo el bosque seco, la sabana arbolada, el palmar y el bosque de ribera presentaron la menor cantidad de especies únicas entre sí (Cuadro 4).

El recambio promedio entre los cinco hábitats fue del $49 \%$, el bosque casmófito (BP) y la sabana arbolada (SA) presentaron la mayor complementariedad (valor más alto de disimilaridad entre par de biotas), seguidos por el bosque casmófito y el palmar, entre tanto el menor reemplazamiento se presenta entre el palmar y el bosque de ribera (Cuadro 4).

Los cinco hábitats compartieron el $22 \%$ de las especies encontradas, solo la especie de serpiente Leptodeira septentrionalis se presentó en todos los hábitats, la proporción restante de especies compartidas son lagartos.

\section{La composición de reptiles del complejo cenagoso de Zapatosa y las registradas para Colombia y el Caribe}

En el complejo de ciénagas de Zapatosa, los reptiles presentaron el 100\% de los órdenes, el $53 \%$ de las familias, el $31 \%$ de los géneros y el $9 \%$ de las especies de las cifras que se presentan para Colombia (Cuadro 5). Mientras que de los registros de las tierras bajas del Caribe, para el complejo cenagoso de Zapatosa se registró el $100 \%$ de los órdenes, el $74 \%$ de las familias, el $63 \%$ de los géneros y el $45 \%$ de las especies (Cuadro 5 y Apéndice 1).

\section{CUADRO 5}

Número de órdenes, familias, géneros y especies de reptiles registrados en el complejo cenagoso de Zapatosa en contraste con los registros para el país y zonas bajas del Caribe. * Reptiles de las zonas bajas del Caribe a partir de los inventarios tomando solo los registros $<500 \mathrm{~m}$ (Referencias en Materiales y métodos)

\section{TABLE 5}

Number of orders, families, genera and species of the reptiles recorded in the Zapatosa's wetland complex in contrast with the records for the country and the Caribbean lowlands. * Reptiles of the Caribbean lowlands taking into account just inventory records $<500 \mathrm{~m}$ (References in Materials and methods)

$\begin{array}{lccc}\text { Colombia } & \begin{array}{c}\text { Zonas bajas } \\ \text { Caribe* }\end{array} & \begin{array}{c}\text { Complejo } \\ \text { Ciénaga de } \\ \text { Zapatosa }\end{array} \\ \text { Orden } & 3 & 3 & 3 \\ \text { Familia } & 32 & 23 & 17 \\ \text { Géneros } & 143 & 70 & 44 \\ \text { Especies } & 515 & 108 & 48\end{array}$


El complejo ciénaga de Zapatosa compartió la mayor cantidad de especies con los humedales de Córdoba (66\%) (Castaño-Mora et al. 2004a, Carvajal-Cogollo 2006, CárdenasArévalo et al. 2010), en tanto que presentó una alta proporción de especies $(61 \%)$ de las registradas para la zona tropical de la serranía de Perijá, Cesar (Moreno-Arias et al. 2009); compartió con la fauna de reptiles registrada para el bosque seco del santuario de vida silvestre de Los Besotes en Valledupar (44\%) (RuedaAlmonacid et al. 2008) y por último con los fragmentos de bosques relictuales de Córdoba (39\%) (Carvajal-Cogollo \& Urbina-Cardona 2008) (Apéndice 1).

\section{DISCUSIÓN}

\section{Riqueza total y representatividad}

La riqueza en el complejo ciénaga de Zapatosa representó una pequeña parte de la fauna de reptiles en Colombia ( 10\%) (Castaño-Mora et al. 2004a). Aunque, no es una fauna tan rica como lo es la chocoana o la andina (Sánchez-C et al. 1995, Castaño-Mora et al. 2004b), es un número proporcionalmente alto de especies en comparación con otros sitios donde se ha muestreado áreas más grandes por lapsos más largos y/o en hábitats estructuralmente más complejos (Bajo Anchicayá Chocó Biogeográfico, Vargas \& Bolaños 1999; alrededores del municipio de Lloró Chocó Biogeográfico, Rengifo et al. 2002; Isla Gorgona, Pacífico colombiano, Urbina-Cardona \& Londoño-Murcia 2003; humedales de la planicie del departamento de Córdoba, CarvajalCogollo et al. 2007; bosques de la Amazonia brasilera, Gardner et al. 2007; Reserva Los Tuxtlas, Veracruz-México, Urbina-Cardona 2007), esto refleja que las condiciones actuales de los ecosistemas de Colombia y de la región aportan estabilidad y recursos estructurales suficientes para el mantenimiento de una alta diversidad de especies de fauna.

En el estudio se registró casi a la mitad de la fauna que se conoce para la región Caribe y una proporción relativamente grande de las especies del departamento del Cesar, pero si se compara concretamente con la franja tropical del departamento el complejo cenagoso de Zapatosa albergó casi todas las especies registradas hasta el momento (Moreno-Arias et al. 2009). Probablemente, los recursos estructurales de las ciénagas le permiten comportarse como un centro de concentración de reptiles en el departamento y en la región. El patrón en la composición coincidió con lo encontrado hasta ahora en las tierras bajas del Caribe y del departamento del Cesar, donde la familia más rica es Colubridae y el género más rico Anolis (Polychrotidae) (Ayala 1986, Sánchez-C. et al . 1995, Hernández-Ruz et al. 2001, CastañoMora et al. 2004a, Moreno-Arias et al. 2009).

El muestreo total alcanzó una representatividad mayor al $80 \%$, ésto sugiere que el estudio logró un porcentaje satisfactorio frente a la riqueza real de especies que posee el complejo (Soberón \& Llorente 1993). Para serpientes y saurios los valores son altos dentro de los parámetros que se han establecido como óptimos para hacer comparaciones válidas entre inventarios o hábitats (Soberón \& Llorente 1993, Urbina-Cardona \& Reynoso 2005); sin embargo, para las serpientes las especies duplicadas no disminuyeron a lo largo del estudio, de manera que los elementos raros del grupo pueden seguir apareciendo durante el muestreo. Los ofidios son componentes poco comunes de diferentes estudios (Urbina-Cardona \& Reynoso 2005, Carvajal-Cogollo et al. 2007, Moreno-Arias \& Medina-Rangel 2007, Carvajal-Cogollo 2008, Moreno-Arias et al. 2008), su menor abundancia es dada por características como la alta dependencia poblacional a la dinámica de sus presas, bajos tamaños poblacionales, hábitos crípticos, etología e historia natural evasiva por lo cual son poco perceptibles a los encuentros visuales en estudios tradicionales (Vitt \& Vangilder 1983, Rugiero \& Luiselli 1995, Luiselli 2006), dificultando su estudio en campo (Carvajal-Cogollo 2008, Urbina-Cardona et al. 2008).

Posiblemente lo anterior sea la causa para que las tres cuartas partes de los elementos raros que alcanzan el $20 \%$ en todo el estudio, 
sean especies de serpientes, cifra bastante menor, si se le compara con otros estudios en la misma región de vida, donde las serpientes son casi todos los elementos raros que se han registrado en dichas investigaciones (CarvajalCogollo et al. 2007, Carvajal-Cogollo 2008, Moreno-Arias et al. 2008).

Si tenemos en cuenta la ecología y características de historia de vida ya mencionadas de las serpientes, podemos hacer comparaciones de mayor alcance entre distintos inventarios de reptiles, si el proceso se efectúa con base en valores de representatividad que tengan como límite inferior un 60\%-70\% como lo sugiere Carvajal-Cogollo (2008) y/o Urbina-Cardona et al. (2008) respectivamente. Además, es más apropiado utilizar estimadores que no produzcan resultados sesgados a la hora de evaluar la riqueza cuando se presenta un número elevado de especies poco comunes, p.e. Boopstrap (Magurran 2004, Urbina-Cardona et al. 2008). También se deben buscar técnicas de muestreo más eficaces para los ofidios e incrementar el esfuerzo de muestreo (Shine \& Bonnet 2000, Urbina-Cardona \& Reynoso 2005, UrbinaCardona et al. 2008), que pudiesen ofrecer más elementos de juicio en el momento de comparar resultados más completos que los actuales y poder contrastar los resultados de distintas investigaciones.

El estudio se encontraron cinco especies endémicas para Colombia: dos lagartos (Sphaerodactylus heliconiae y Stenocercus erythrogaster), dos serpientes (Helicops danieli y Thamnodynastes gambotensis) y dos tortugas (Podocnemis lewyana y Mesoclemmys dahli); adicionalmente, siete especies tenían algún grado de amenaza en su conservación dentro del país: cinco tortugas (Podocnemis lewyana EN, Mesoclemmys dahli EN, Chelonoidis carbonaria CR, Kinosternon scorpioides VU y Trachemys callirostris NT) y dos cocodrilos (Crocodylus acutus CR y Caiman crocodilus LC) (Castaño-Mora 2002); de tal forma se ha mostrado la importancia de la zona como refugio de fauna propia del país.

\section{Diversidad alfa por hábitats}

El muestreo de los hábitats alcanzó una representatividad de media a baja en comparación con todo el estudio, e intermedia si se les compara con otras investigaciones en la misma zona de vida con ambientes similares, en las que se aplicaron esfuerzos de muestreo menores y donde la representatividad fluctúo entre $46 \%$ y 95\% (Carvajal-Cogollo et al. 2007, Gardner et al. 2007, Carvajal-Cogollo 2008). El hábitat en que pareció haberse subestimado la riqueza de especies fue el palmar, mientras que los demás tipos de hábitat estuvieron bien muestreados, este resultado sugiere que el estudio logró un porcentaje satisfactorio para casi todos los hábitats frente a la riqueza real de especies del complejo (Soberón \& Llorente 1993). Es posible que para alcanzar una más alta representatividad de especies y llegar a estimaciones superiores a las encontradas en la riqueza, se deba invertir más tiempo de muestreo.

Para los grupos taxonómicos como serpientes, el porcentaje de representatividad del muestreo al igual que la tendencia general fue baja en relación a los saurios. Para las tortugas y los cocodrilos también fue baja la representatividad del muestreo, lo cual puede deberse a que los mismos estuvieron enfocados principalmente en ambientes terrestres. Para las serpientes las curvas no alcanzan la asíntota, lo cual indica que hay posibilidades de que nuevas especies aparezcan a lo largo del estudio si se continúa con el muestreo. Como se había mencionado antes las serpientes presentan inconvenientes en los estudios de diversidad (Vitt \& Vangilder 1983, Luselli 2006, Urbina-Cardona et al.2008), situación que se refleja en general en la baja representatividad en el muestro de diferentes estudios y particularmente en cada hábitat. Los saurios enseñan una representatividad alta, sus valores alcanzan la asíntota, es decir que hay menores probabilidades de que surjan nuevas especies al continuar con el muestreo. La baja frecuencia de aparición de las serpientes dentro de los hábitats podrían 
estar más influenciada por sus hábitos de forrajeo y tróficos (Calderón-Mandujano et al. 2008), mientras que los saurios podrían estar más influenciados por la estructura del hábitat (Ríos-López \& Mitchell 2007), razón por la cual conseguirían ser registrados con mayor frecuencia en el estudio y alcanzar los más altos porcentajes de representatividad.

Varias especies presentaron amplia distribución, se encontraron en casi todos los tipos de hábitats, como es el caso de Gonatodes albogularis, Cnemidophorus lemniscatus, Ameiva ameiva, Leptodeira septentrionalis, Thamnodynastes gambotensis, Basiliscus basiliscus, Tupinambis teguixin, Anolis tropidogaster, Anolis auratus, Imantodes cenchoa, Leptophis ahaetulla, Bothrops asper, Iguana iguana, Thecadactylus rapicaudus y Tretioscincus bifasciatus. Estas especies además mostraron valores altos de abundancias, por lo cual podrían ser favorecidas por algunas de las condiciones y recursos que les ofrecen las zonas bajas con cierto grado de intervención, al igual que se registró en otros estudios en la franja tropical del Caribe (Carvajal-Cogollo 2006, Carvajal-Cogollo et al. 2007, Carvajal-Cogollo 2008, Moreno-Arias et al. 2009).

El bosque de ribera es el hábitat con la más alta riqueza y diversidad de especies en la zona de estudio, algunas especies de reptiles se asocian casi de forma exclusiva a hábitats con permanente presencia de agua o a la vegetación en el borde o flotante, por ejemplo las tortugas (Kinosternon scorpioides, Mesoclemmys dahli, Rhinoclemys melanosterna y Trachemys callirostris), la babilla (Caiman crocodilus), dos saurios (Tupinambis teguixin y Basiliscus basiliscus) y una especie de serpiente (Helicops danieli). Estas especies se relacionan más a este tipo de ambientes en cuanto a forrajeo y desarrollo de sus historias naturales, de acuerdo con el ciclo dinámico que liga a muchas especies a los cambios espaciales de las ciénagas u otro tipo de cuerpos de agua (Paton 2005, Bauer \& Jackman 2008, Bour 2008, Martin 2008, Pauwells et al. 2008). El recurso léntico favorece el establecimiento de poblaciones permanentes que ocupan estos espacios; la mayoría actualmente en riesgo (Castaño-Mora 2002) y seguramente caracterizados por la pérdida de este tipo de hábitat.

Parece que hay una mayor estabilidad y grado de conservación del bosque de ribera que ha favorecido el establecimiento y permanencia de las especies del complejo cenagoso frente a los de otros lugares en la misma región. Cárdenas-Arévalo et al. (2010), encontraron que este mismo tipo de hábitat en Córdoba presentaba una baja diversidad y abundancia de especies condición que atribuyen a la alta transformación a la que han sido sometidos; la cual se vuelve muy diferente comparada con la del complejo cenagoso de Zapatosa.

El bosque seco presenta una riqueza intermedia y una mayor abundancia con respecto a casi todos los demás hábitats (excepto $\mathrm{BR}=196$ ind.), pero al estandarizar la muestra a un número igual de individuos capturados, tanto el bosque seco como el palmar presentan una cantidad similar de especies con la sabana arbolada, no obstante como el palmar presentó el mayor sub-muestreo en comparación con los demás, se podría pensar que la diversidad y riqueza de este tipo de ambiente puede ser aún mayor de lo esperado.

Las características térmicas de las especies de la familia Teiidae las hace exitosas en sitios con alta radiación solar, como las sabanas arboladas o sitios despejados, puesto que por ser animales de forrajeo activo, necesitan alta cantidad de energía-radiación para activar el metabolismo de sus cuerpos con tamaños corporales en promedio grandes y así poder forrajear, en la utilización de la búsqueda visual y discriminación vomeronasal de alimento (Vitt et al. 1997, Vitt \& Pianka 2004), lo que les permite explotar recursos alimenticios mucho más amplios frente a otros grupos (Blázquez 1996, Vitt \& Pianka 2005). Pero se vuelven escasos en los bosques casmófitos, hábitats también con alta exposición a los rayos solares; puede ser que especies como Stenocercus erythrogaster ocupen mejor los espacios en sitios con pendiente, ya que es una lagartija rupícola que tiene preferencias por zonas con pendiente de media a fuerte para sus actividades de forrajeo 
y subsistencia (Harvey et al. 2004, TorresCarvajal 2007), por lo cual estaría remplazando a las especies de Teiidae que al parecer presentaron bajo rendimiento en sitios inclinados, de tal manera los aspectos topográficos muestran tienen una fuerte influencia en la presencia de algunas especies (How \& Dell 2000, UrbinaCardona et al. 2006, Carvajal-Cogollo 2008).

Las familias Polychrotidae y Gekkonidae presentan el mayor número de individuos en hábitats con una estructura vertical presente (arboles o arbustos), los Polychrotidae tienen estrategias de consecución de alimentos que dependen más de esperar y atrapar (Losos 1992, 1994), además tienen aprensión lingual a diferencia de los Scleroglossa -p.e. Teiidaeque poseen aprehensión mandibular de las presas (Vitt \& Pianka 2005), por lo cual requieren de sitios con algún grado de estructura que les otorguen un camuflaje y perchas para esperar y emboscar a las presas (Losos 1992, Losos et al. 1997). Los Gekkota presentan estrategias de consecución de alimentos mediadas por el olfato que junto a la aprensión del alimento mandibular acompañan sus estrategias de forrajeo activo de forma constante (Pough et al. 1998, Vitt \& Pianka 2005), es decir combinan parte de las estrategias de los Teiidae y Polychrotidae para conseguir alimento, su tamaño pequeño seguramente es un limitante para presentar valores altos en abundancia y diversidad en ambientes abiertos, pues limita al grupo a explotar sitios por lo menos algo complejos en estructura vegetal (mayor número de estratos).

El bosque de ribera es el ambiente más heterogéneo en la vegetación, sin embargo, al comparar los hábitats entre sí, no hay diferencia estadísticamente significativa entre ellos en composición de reptiles, al tener en cuenta que algunos de estos ambientes son estados sucesionales desde tempranos hasta avanzados (Rangel-Ch. et al. 2008), tienden a tener entre sí una variación similar en su diversidad (RíosLópez \& Mitchell 2007, Calderón-Mandujano et al. 2008). La composición de la comunidad de reptiles solo mostró diferencias en las sabanas arboladas, seguramente aquí la ausencia de una cobertura arbórea cambia condiciones macro y microclimáticas que solo permiten la permanencia de especies con amplio espectro de tolerancia; esta composición se relaciona con múltiples gradientes ambientales y la estructura de la comunidad puede verse influenciada por alteraciones y la presencia humana (Gibbons et al. 2000, Gardner et al. 2007).

Las especies que más contribuyen a la disimilitud en la composición de especies entre hábitats son Gonatodes albogularis, Anolis tropidogaster y Anolis auratus, que cuentan amplia tolerancia y numerosas poblaciones en la franja tropical (Ayala \& Castro: documento inédito, Lagartos de Colombia/Lizards of Colombia. Volumen I-V. Colombia. 820 pp.); como ya se mencionó Stenocercus erythrogaster genera la mayor proporción de la disimilitud del bosque casmófito con respecto a los otros hábitats, posiblemente las características ecológicas de la especie son favorecidas por las condiciones de este ambiente que a su vez restringen la colonización y permanencia de otro tipo de especies en general comunes a lo largo de todo el muestreo (How \& Dell 2000, Torres-Carvajal 2007).

Adicionalmente, el conjunto de hábitats presenta una baja dominancia de especies. Si observamos la uniformidad que los datos muestran, exhiben en general un alto equilibrio en cuanto a la composición de especies de reptiles e indican una estabilidad media a alta en la constitución y distribución de la comunidad (Magurran 1989). Los reptiles fisiológicamente presentan flexibilidad térmica en distintos ambientes (Pianka 1967, Inger et al. 1987), los sitios abiertos y con condiciones térmicas fluctuantes tienden a favorecer la presencia de especies heliotérmicas generalistas como Ameiva ameiva, Ameiva festiva, Cnemidophorus lemniscatus, Gonatodes albogularis y Leptodeira septentrionalis que encuentran los recursos adecuados para subsistir, mientras que el impacto de la transformación de los hábitats genera una reducción o aislamiento en especies que necesitan de ambientes estables en estructura y disponibilidad de recursos en el tiempo como Bachia bicolor, Sphaerodactylus 
heliconiae, Rhinoclemys melanosterna o Enulius flavitorques.

\section{Diversidad beta - recambio de especies entre hábitats}

Los resultados sobre recambio promedio entre todos los hábitats son similares a los mencionados en estudios en la misma zona de vida y tipo de ecosistema (Carvajal-Cogollo et al. 2007), pero un $49 \%$ de recambio es bajo en comparación con los de otros ecosistemas muestreados en otras regiones, donde la complementariedad alcanza hasta el $78 \%$ (Pineda \& Halffter 2004); Urbina-Cardona \& Londoño-Murcia (2003), Carvajal-Cogollo et al. (2007) y Carvajal-Cogollo (2008) registraron un recambio muy parecido en sus estudios, con valores aproximados también al 50\% de complemento entre hábitats en ambientes tan disímiles como bosque seco y bosque superhúmedo. La complementariedad depende de la oferta de recursos en cada uno de los hábitats y los recursos que estos ofrecen al componente de fauna son distintos, por lo cual la biota que se establece, cambia de acuerdo con sus necesidades de explotación de recursos alimenticios y espaciales (Halffter \& Moreno 2005). El complejo cenagoso de Zapatosa ofrece una heterogeneidad ambiental intermedia si se le compara con otros estudios (Urbina-Cardona \& Londoño-Murcia 2003, Pineda \& Halffter 2004, Carvajal-Cogollo et al. 2007, CarvajalCogollo 2008).

El bosque casmófito es el hábitat que presenta la más alta complementariedad y el mayor número de especies únicas entre pares de biotas. Cuando se le compara con los demás, puede ser como ya se sugirió que la topografía, condiciones del sustrato y la vegetación de este tipo de hábitat generan un mayor recambio de especies, si tenemos en cuenta que la diferenciación de las biotas es afectada por la discontinuidad abrupta o gradual en la estructura del ambiente en el espacio (Halffter \& Moreno 2005, Rodríguez \& Arita 2005), la diversidad beta incrementa con la variabilidad ambiental y a pesar de presentar el menor número de especies favorece que muchas de ellas se encuentren asociadas parcial o totalmente con este hábitat.

El bosque de ribera presentó el mayor número de especies compartidas con casi todos los demás hábitats y la mayor cantidad de especies exclusivas. La estabilidad en cuanto a la presencia constante de agua y microclima más húmedo puede favorecer que las especies encuentren mejores condiciones para subsistir o forrajear de forma temporal o permanente; es el caso de algunas de esas especies exclusivas como Enulius flavitorques y Spilotes pullatus que podrían ser consideradas visitantes ocasionales o especies raras, puesto que sólo aparecieron una vez dentro del muestreo y no pueden ser consideradas como exclusivas de este tipo de hábitats dada su historia natural (Pérez-Santos \& Moreno 1988), pues se les ha registrado en ambientes más secos y con una menor estructura vegetal como en sabanas arboladas de Córdoba (Carvajal-Cogollo et al. 2007, Carvajal-Cogollo 2008).

La mayor cantidad de especies de reptiles que se comparten entre hábitats, pertenecen al grupo de los saurios, solo una pequeña proporción de serpientes $(<25 \%)$, es común entre los distintos ambientes, posiblemente la rareza del grupo de ofidios defina que el patrón de complementariedad también sea bajo. En la región únicamente la serpiente Leptodeira septentrionalis se encontró en todos los hábitats, sus características ecológicas la hacen una especie generalista, capaz de aprovechar de forma exitosa los recursos que se presentan a su disposición (Pérez-Santos \& Moreno 1988, Duellman 1990).

Para efectos de conservación, es importantes preservar los relictos con bosques casmófito y los bosques de ribera como prioridad. El alto recambio de especies que se presenta entre ellos y otros tipos de hábitats y la diversidad de especies que contienen, aseguraría la supervivencia y permanencia de más del $70 \%$ de las especies de la zona, siempre y cuando se mantenga un uso del suelo de bajo impacto alrededor de los fragmentos para amortizar los efectos de borde. Sin embargo, no deben 
relegarse los palmares y el bosque seco, ya que también albergan una alta diversidad de especies y al parecer algunas de las que solamente se encuentran en estos tipos de hábitats dependen de su estructura vegetal, por lo cual es importante identificar hábitats estratégicos para conservar en los alrededores del complejo de ciénagas conectados entre sí, y asegurar la supervivencia de la mayor proporción de especies de reptiles.

\section{Composición de reptiles del complejo ciénaga de Zapatosa frente a lo registrado para el Caribe y Colombia}

La posición geográfica y condiciones específicas del complejo cenagoso son de alto valor para la conservación de la zona, dado que contiene casi dos tercios de la riqueza de reptiles del departamento y casi todas las especies de la zona tropical del mismo departamento, además de contener una alta diversidad de especies de otros vertebrados en general (Rangel-Ch. 2008) y proveer beneficios al clima local y regional, bienestar y recursos a la población humana aledaña, entre otros servicios ambientales.

Si se comparan los resultados de la presente investigación con los de otras zonas bajas del país, es claro que los sitios cercanos y de condiciones ecológicas más o menos similares como los humedales de Córdoba (Castaño-Mora et al. 2004a) y el santuario de vida silvestre de Los Besotes (Rueda-Almonacid et al. 2008), comparten con el complejo cenagoso la mayor cantidad de especies. Los resultados señalados podrían estar indicando una baja diversidad beta en la región que puede estar comportándose como un continuo, donde procesos de tipo biogeográfico y ecológico pueden ser responsables de la alta similitud entre las zonas (Duellman 1979, Cadle 1985, Estes \& Báez 1985).

En este trabajo el complejo cenagoso de Zapatosa aparece con un menor número de especies que el conjunto de ciénagas de Córdoba (Castaño-Mora et al. 2004a). El resultado puede deberse a efectos del esfuerzo de muestreo, puesto que Córdoba ha tenido una mayor cantidad y extensión de tiempo de estudio, además se ha trabajado en dos cuencas la del río Sinú y la del San Jorge, en enclaves húmedos que pueden aumentar la complejidad faunística del sector. Además, Córdoba presenta una fuerte influencia de la fauna del Pacífico, dada su posición geográfica, que le aporta elementos del Chocó Biogeográfico a su fauna (Carvajal-Cogollo 2008, Carvajal-Cogollo \& Urbina-Cardona 2008), mientras Zapatosa presenta elementos que pueden derivarse de localidades ubicadas más al norte (Rueda-Almonacid et al.2008) e influencia marcada de la fauna de la serranía del Perijá (Moreno-Arias \& Medina-Rangel 2007, Moreno-Arias et al. 2008, Moreno-Arias et al. 2009), que si se comparan al Chocó Biogeográfico seguramente no son suficientes para equiparar el aporte del bosque húmedo de Pacífico a Córdoba frente a lo que podría enriquecer el componente de especies del complejo de ciénagas en el Cesar.

La diversidad teórica de reptiles podría ser mayor a la encontrada, pero quizás en la práctica estos valores no tengan mucha variación debido a la marcada fragmentación de los ambientes de la región Caribe (IAvH 1998, Rangel-Ch. 2000). También hay que tener en cuenta que los procesos de destrucción en los hábitats de la zona, producto de la ganadería intensiva, quemas, agricultura, contaminación (pesticidas y agroquímicos), basuras y cultivo de especies foráneas de plantas, p.e. palma africana Elaeis guineensis, tiende a generar cambios y fuertes presiones que necesariamente se expresan sobre la diversidad en la región.

En síntesis y finalmente para concluir se puede afirmar que:

El número de especies de reptiles que se encontró en la zona de estudio, representa una alta proporción de la fauna de la región, constituye la mitad de las registradas para el Caribe y más de las tres cuartas partes de las especies en común a otros estudios en zonas adyacentes a humedales en la misma región.

El bosque de ribera presentó los mayores valores de riqueza y abundancia de las especies de reptiles dentro de todo el estudio, mientras que el bosque casmófito mostró el menor 
número de especies y la sabana arbolada la más baja abundancia.

Las serpientes son los elementos con la más baja representatividad dentro de los Squamata para todo el estudio y también en cada uno de los hábitats.

Especies como Gonatodes albogularis, Anolis tropidogaster, Anolis auratus, Cnemidophorus lemniscatus, Iguana iguana, Thecadactylus rapicauda, Lepidoblepharis sanctaemartae, Leptophis ahaetulla y Leptodeira septentrionalis, utilizan una amplia gama de hábitats y tienen abundancias considerables que parecen ser favorecidas por algunas de las condiciones y recursos que les ofrecen las zonas bajas con cierto grado de intervención y hábitats aledaños a humedales continentales.

La complementariedad media entre todos los hábitats muestreados en el complejo de ciénagas de Zapatosa alcanza casi el 50\%; los mayores valores de recambio se presentan entre el bosque casmófito y los otros cuatro hábitats, lo cual muestra que este hábitat presenta la mayor particularidad en cuanto a su composición de especies y que a pesar de tener la menor riqueza es el ambiente que más aporta al recambio en toda el área de estudio.

La baja diversidad beta de la región implica que los hábitats pueden estar comportándose como un continuo donde procesos de tipo biogeográfico y ecológico pueden ser responsables de la alta similitud entre las zonas, lo que puede implicar que conservar una zona representativa de todos los ambientes que se encuentran, garantizaría la subsistencia de una alta proporción de las especies presentes en la región.

\section{AGRADECIMIENTOS}

Al grupo de Biodiversidad y Conservación del Instituto de Ciencias Naturales y CORPOCESAR por el apoyo y financiación del presente estudio. A mis directores del proyecto J. Orlando Rangel-Ch. y Olga Victoria Castaño por su apoyo y valiosas sugerencias durante el desarrollo del presente estudio. A Gladys Cárdenas por sus valiosas sugerencias en la construcción del presente documento y apoyo durante la fase de campo en los muestreos en la zona. A Jimena Cortés y Juan Carvajal por su apoyo en campo durante el muestreo en la zona de estudio. A mis amigos y compañeros del grupo de reptiles: Gladys Cárdenas, Adriana González, Jimena Cortés, Juan Carvajal y Rafael Moreno, que siempre me brindaron su apoyo y valiosas sugerencias para mejorar el proyecto. A Lina Rocío Campos por su amor. A las personas de Chimichagua, Saloa, Potrerillo, y La Loma que me apoyaron y recibieron con cariño durante mi fase de campo en la zona; en especial al señor Saúl Reyes y su familia, Germán Payán e hijo, señora Kelly y su familia, Juan Carlos Moreno, Luis Pérez, Elizabeth Reales y Rodolfo Cabrales que con su hospitalidad y cariño hicieron mejor nuestra estadía. Finalmente, gracias a los evaluadores anónimos del artículo por sus oportunas $\mathrm{y}$ valiosas sugerencias.

\section{RESUMEN}

La diversidad es una propiedad de las comunidades, permite describir, caracterizar y entender el funcionamiento de los ecosistemas. Para estudiar la riqueza, abundancia y el recambio de especies de reptiles entre hábitats circundantes al complejo cenagoso de Zapatosa, se realizaron cuatro salidas de campo (noviembre de 2006 y octubre de 2007). Se invirtieron $640 \mathrm{~h} /$ hombre de muestreo repartido en cinco tipos de hábitat: bosque casmófito, bosque seco, bosque de ribera, palmar y sabana arbolada. Se encontraron 847 individuos de 48 especies, la familia más rica fue Colubridae, se registraron cinco especies endémicas y ocho con algún grado de amenaza en conservación a nivel nacional. El hábitat más diverso fue el bosque de ribera. La representatividad del muestreo en total y para cada hábitat fue superior al $80 \%$, con excepción del palmar $(<75 \%)$. La composición de especies fue diferente entre la sabana arbolada y los hábitats bosque de ribera, palmar y bosque seco. El recambio promedio de especies fue del $50 \%$. El bosque casmófito mostró la mayor complementariedad y número de especies únicas. El complejo cenagoso presentó 2/3 de los reptiles registrados hasta hoy para la región Caribe y más del $80 \%$ de los encontrados para el departamento del Cesar.

Palabras clave: diversidad alfa y beta, lagartos, serpientes, tortugas y cocodrilos, composición y estructura, complejo cenagoso de Zapatosa, Colombia. 


\section{REFERENCIAS}

Angulo, A., A. La Marca, J.V. Rodríguez \& J.V. Rueda. 2006. Técnicas de inventario y monitoreo para los anfibios de la región tropical andina. Conservación Internacional-Serie de guías tropicales de campo 4. Bogotá D.C., Colombia.

August, D. 1983. The role of habitat complexity and heterogeneity in structuring tropical mammal communities. Ecology 64: 1495-1507.

Ayala, S. 1986. Saurios de Colombia, lista actualizada y distribución de ejemplares colombianos en los museos. Caldasia 15: 71-75.

Barbosa-Castillo, C., C.A. Ruíz-Agudelo, H. García-Quiñones \& T.D. Gutiérrez. 2008. Guía ilustrada de plantas destacadas del Santuario de Vida Silvestre Los Besotes, Valledupar, Cesar, Colombia, p. 1-246. In J.V. Rodríguez-Mahecha \& W. Márquez (eds.). Series de guías tropicales de campo $\mathrm{N}^{\circ} 8$. Conservación Internacional Colombia, Panamericana, Formas e Impresos, Bogotá, Colombia.

Bauer, A.M. \& T. Jackman. 2008. Global diversity of lizards in freshwater (Reptilia: Lacertilia). Hydrobiologia 595: 581-586.

Blázquez, M.C. 1996. Activity and habitat use in a population of Ameiva ameiva in Southeastern Colombia. Biotropica 28: 714-719.

Bernal-Carlo, A. 1991. Herpetology of Sierra Nevada de Santa Marta, Colombia: a biogeographical analysis. Ph.D. Thesis, City University of New York, Nueva York, EEUU.

Bour, R. 2008. Global diversity of turtles (Chelonii; Reptilia) in freshwater. Hydrobiologia 595: 593-598.

Calderón-Mandujano, R.R., C. Galindo-Leal \& J.R. Cedeño-Vázquez. 2008. Utilización del hábitat por reptiles en estados sucesionales de selvas tropicales de campeche, México. Acta Zool. Mex. 24: 95-114.

Cadle, J.E. 1985. The Neotropical colubrid snake fauna (Serpentes: Colubridae): lineage components and biogeography. Syst. Zool. 34: 1-20.

Campbell, J. \& W. Lamar. 2004. The venomous reptiles of the western hemisphere. Comstock, Ithaca, Nueva York, EEUU.

Cárdenas-Arévalo, G., O.V. Castaño-Mora \& J.E. CarvajalCogollo. 2010. Comunidad de reptiles en humedales y áreas aledañas del departamento de Córdoba, p. 361-380. In J.O. Rangel-Ch. (ed.). Colombia diversidad biótica IX: ciénagas de Córdoba: biodiversidad-ecología y manejo ambiental. Instituto de Ciencias Naturales-Universidad Nacional de Colombia, Bogotá D.C., Colombia.

Carvajal-Cogollo, J.E. 2006. Conservación de reptiles, p. 311-342. In J.O. Rangel-Ch. (ed.). Informen final diagnostico ambiental y ecológico y plan de manejo de los humedales del río San Jorge y Sinú. Convenio interadministrativo. Universidad Nacional de Colombia-Instituto de Ciencias Naturales-CVS Corporación Autónoma Regional de los Valles del Sinú y San Jorge. Bogotá D.C., Colombia.

Carvajal-Cogollo, J.E., O.V. Castaño-Mora, G. CárdenasArévalo \& J.N. Urbina-Cardona. 2007. Reptiles de áreas asociadas a humedales de la planicie del departamento de Córdoba, Colombia. Caldasia 29: 427-438.

Carvajal-Cogollo, J.E. 2008. Evaluación de efectos antropogénicos sobre la diversidad de reptiles de un bosque fragmentado en el departamento de Córdoba, Colombia. MSc. Tesis, Universidad Nacional de Colombia, Colombia.

Carvajal-Cogollo, J.E. \& J.N. Urbina-Cardona. 2008. Patrones de diversidad y composición de reptiles en fragmentos de bosque seco tropical en Córdoba, Colombia. Trop. Conserv. Science 1: 397-416.

Castaño-Mora, O.V. 1992. Tortugas de Colombia. Informe final a Conciencias del proyecto: "Las tortugas de Colombia, Fase II". Universidad Nacional de Colombia-Colciencias, Bogotá D.C., Colombia.

Castaño-Mora, O.V. 2002. Libro rojo de reptiles de Colombia. Libros rojos de especies amenazadas de Colombia. Instituto de Ciencias Naturales-Universidad Nacional de Colombia, Ministerio de Medio Ambiente, Conservación Internacional-Colombia. Bogotá D.C., Colombia.

Castaño-Mora, O.V., G. Cárdenas, P.A. Galvis \& E. Hernández-Ruz. 1997. Reptiles, p. 168-190. In J.O. Rangel-Ch. (ed.). Informen final del estudio de la flora y de la fauna Sistema Andino de la Serranía del Perijá. Instituto de Ciencias Naturales. Universidad Nacional de Colombia-CORPOCESAR Corporación Autónoma Regional del Cesar. Bogotá D.C., Colombia.

Castaño-Mora, O.V., G. Cárdenas, J.E. Carvajal-Cogollo \& O. Ruiz. 2004a. Reptiles, p. 293-342. In J.O. Rangel-Ch. (ed.). Informen final de flora y fauna de los humedales de Córdoba. Instituto de Ciencias Naturales. Universidad Nacional de Colombia-CVS Corporación Autónoma Regional de los Valles del Sinú y San Jorge. Bogotá D.C., Colombia. 
Castaño-Mora, O.V., G. Cárdenas, E. Hernández-Ruz \& F. Castro. 2004b. Reptiles en el Chocó Biogeográfica-Catalogo, p. 599-632. In J.O. Rangel-Ch. (ed.). Colombia Diversidad Biótica IV: El Chocó biogeográfico/Costa Pacífica. Instituto de Ciencias Naturales, Universidad Nacional de Colombia, Bogotá D.C., Colombia.

Ceballos-Fonseca, C.P. 2000. Tortugas (Testudinata) marinas y continentales de Colombia. Biota Colombiana 1: 187-194.

Chapin, F.S., E.S. Zabaleta, V.T. Eviner, R.L. Naylor, P.M. Vitousek, H.L. Reynolds, D.U. Hooper, S. Lavorel, O.E. Sala, S.E. Hobbie, M.C. Mack \& S. Díaz. 2000. Consequences of changing biodiversity. Nature 405 : 234-242.

Clarke, K.R. 1993. Non-parametric multivariate analysis of changes in community structure. Aust. J. Ecol. 18: 117-143.

Clarke, K.R. \& R.N. Gorley. 2001. Primer (Plymouth Routines In Multivariate Ecological Research) v5: user manual/tutorial. Primer-E, Plymouth, EEUU.

Colwell, R.K. \& J.A. Coddington. 1994. Estimating terrestrial biodiversity through extrapolation. Philos. T. Roy. Soc. B. 345: 101-118.

Colwell, R.K. 2005. EstimateS: Statistical estimation of species richness and shared species from samples. Version 7.5. User's guide and application. Department of Ecology and Evolutionary Biology, University of Connecticut, Storrs. (Available from: http://purl.oclc.org/estimates).

Crump, M.L. \& N.J. Scott. 1994. Visual encounters surveys, p. 354-352. In W. Heyer, M. Donelly, R. McDiarmid, L. Hayek \& M. Foster (eds.). Measuring and monitoring biological diversity, standard methods for amphibians. Smithsonian, Washington, EEUU.

Duellman, W.E. 1979. A South American herpetofauna: a panoramic view, p. 1-28. In W.E. Duellman (ed.). The South American herpetofauna: its origin, evolution, and dispersal. Mus. Nat. Hist. University of Kansas. Lawrence, Kansas, EEUU.

Duellman, W.E. 1990. Herpetofaunas Neotropical rainforest: comparative composition, history and resource use, p. 455-505. In A.H. Gentry (ed.). Four Neotropical Rainforest. Yale University, New Haven, EEUU.

Estes, R. \& A. Báez. 1985. Herpetofauna of North and South America during the late Cretaceous and Cenozoic: evidence of interchange?, p. 139-197. In F.G.
Stchli \& S.D. Webb (eds.). The great American biotic interchange. Plenum, Nueva York, EEUU.

Feinsinger, P. 2001. Designing field studies for diversity conservation. Island, Washington D.C., EEUU.

Garden, J.G., C.A. McAllpine, H.P. Possingham \& D.N Jones. 2007. Habitat structure is more important than vegetation composition for local-level management of native terrestrial reptiles and small mammal species living in urban remmants: A case study from Brisbane, Australia. Austral Ecol. 32: 669-685.

Gardner, T.A., M.A. Ribeiro-Junior, J. Barlow, T.C.S Ávila-Pires, M.S. Hoogmoed \& C.A. Pérez. 2007. The value of primary, secondary, and plantation forests for a neotropical herpetofauna. Conserv. Biol. 21: 775-787.

Gibbons, J.W., D.E. Scott, T.J. Ryan, K.A. Buhlmann, T.D. Tuberville, B.S. Metts, J.L. Greene, T. Mills, Y. Leiden, S. Poppy \& C.T. Wine. 2000. The global decline of reptiles, déja vu amphibians. Bioscience 50: 653-666.

Gotelli, N.J. \& R.K. Colwell. 2001. Quantifying biodiversity: procedures and pitfalls in the measurement and comparison of species richness. Ecol. Lett. 4: 379-391.

Greene, H.W. 2005. Historical influences on community ecology. P. Natl. Acad. Sci. USA. 102: 8395-8396.

Hair, J. 1987. Medida de la diversidad ecológica, p. 283289. In T.R. Rodríguez (ed.). Manual de técnicas de gestión de vida silvestre. Wildlife Society, Maryland, EEUU.

Halffter, G. \& C.E. Moreno. 2005. Significado biológico de las diversidades alfa, beta y gamma, p. 5-18. In G. Halffter, J. Soberón, P. Koleff \& A. Meliá (eds.). Sobre diversidad biológica: el significado de las diversidades alfa, beta y gamma. Monografías tercer milenio, Sociedad Entomológica Aragonesa, Zaragoza, España.

Hammer, O., D.T.A. Harper \& P.D. Ryan. 2001. PAST: paleontological statistics software package for education and data analysis. Palaeontol. Electron. 4: 1-9.

Harvey, M.B., G.A. Rivas \& J. Manzanilla. 2004. Redescription of Stenocercus erythrogaster (Hallowell). Copeia 2004: 940-944.

Hernández-Ruz, E., O.V. Castaño-Mora, G. CárdenasArévalo \& P.A. Galvis-Peñuela. 2001. Caracterización preliminar de la "comunidad" de reptiles de un sector de la serranía del Perijá, Colombia. Caldasia 23: 475-489. 
Heyer, W., M. Donelly, R. McDiarmid, L. Hayek \& M. Foster (eds.). 1994. Measuring and monitoring biological diversity, standard methods for amphibians. Smithsonian, Washington, EEUU.

How, R.A. \& J. Dell. 2000. Ground vertebrate fauna of Perth's vegetation remnants: Impact of 170 years of urbanization. Pac. Conserv. Biol. 6: 198-217.

Instituto de Investigación de Recursos Biológicos Alexander von Humboldt. IAvH. 1998. El Bosque seco Tropical (Bs-T) en Colombia. Programa de inventario de la Biodiversidad, Grupo de exploraciones y monitoreo ambiental GEMA. (también disponible en línea: http://www.humboldt.org.co/download/inventarios/bst/Doc3.pdf).

Inger, R.F., H.B. Shaffer, M. Koshy \& R. Bakde. 1987. Ecological structure of a herpetological assemblage in South India. Amphibia-Reptilia 8: 189-202.

Jellinek, S., D.A. Driscoll \& J.B. Kirkpatrick. 2004. Environmental and vegetation variables have a greater influence than habitat fragmentation in structuring lizard communities in remnant urban bushland. Austral Ecol. 29: 294-304.

Losos, J.B. 1992. The Evolution of convergent structure in caribbean Anolis Communities. Syst. Biol. 41: 403-420.

Losos, J.B. 1994. Historical contingency and lizard community ecology, p. 319-333. In L.J. Vitt \& E.R. Pianka (eds.). Lizard ecology: historical and experimental perspectives. Princeton, Nueva Jersey, EEUU.

Losos, J.B., K.I. Warheit \& T.W. Schoener. 1997. Adaptive differentiation following experimental island colonization in Anolis lizards. Nature 387: 70-73.

Luiselli, L. 2006. Resource partitioning and interspecific competition in snakes: the search for general geographical and guild patterns. Oikos 114: 193-211.

Magurran, A.E. 1989. Ecological diversity and its measurement. Princeton, Nueva Jersey, EEUU.

Magurran, A.E. 2004. Measuring biological diversity. Blackwell, Oxford, United Kingdom.

Martin, S. 2008. Global diversity of crocodiles (Crocodilia, Reptilia) in freshwater. Hydrobiologia 595: 587-591.

May, R.M. 1975. Patterns of species abundance and diversity, p. 81-120. In M.L. Cody \& J.M. Diamond (eds.). Ecology and evolution of communities. Belknaps, Harvard, Massachusetts, EEUU.
Medina-Rangel, G.F. \& G.A. Forero-Medina. 2008. Geographical distribution Mesoclemmys dahli. Herpetol. Rev. 39: 366.

Moreno, C.E. 2001. Métodos para medir la biodiversidad. Manuales \& Tesis SEA, vol. 1, CYTED, ORCYTUNESCO \& SEA, Zaragoza, España.

Moreno-Arias, R.A. \& G.F. Medina-Rangel. 2007. Herpetofauna de la Serranía del Perijá, Colombia, p. 193201. In J.O. Rangel-Ch. (ed.). Colombia Diversidad biótica V: La alta montaña de la Serranía del Perijá, Colombia. Instituto de Ciencias Naturales-Universidad Nacional de Colombia- CORPOCESAR, Bogotá D.C., Colombia.

Moreno-Arias, R.A., G.F. Medina-Rangel \& O.V. CastañoMora. 2008. Lowland reptiles of Yacopí (Cundinamarca, Colombia). Rev. Acad. Colomb. Cienc. Exactas, Fis. Nat. 32: 93-103.

Moreno-Arias, R.A., G.F. Medina-Rangel, O.V. CastañoMora \& J.E. Carvajal-Cogollo. 2009. Herpetofauna de la Serranía del Perijá, Colombia, p. 449-470. In J.O. Rangel-Ch. (ed.). Colombia Diversidad biótica VIII: La Serranía del Perijá, Colombia. Instituto de Ciencias Naturales-Universidad Nacional de Colombia- CORPOCESAR, Bogotá D.C., Colombia.

Páez, V.P., B.C. Bock, J.J. Estrada, A.M. Ortega, J.M. Daza \& P.D. Gutiérrez-C. 2002. Guía de campo de algunas especies de anfibios y reptiles de Antioquia. Colciencias Multimpresos, Medellín, Colombia.

Paton, P.W.C. 2005. A review of vertebrate community composition in seasonal forest pools of the northeastern United States. Wetl. Ecol. Manag. 13: 235-246.

Pauwells, O.S.G., Van Wallach \& P. David. 2008. Global diversity of snakes (Serpentes; Reptilia) in freshwater. Hydrobiologia 595: 599-605.

Pérez-Santos, C. \& A.G. Moreno. 1986. Las serpientes del Atlántico. Museo Nacional de Ciencias Naturales, Madrid, España.

Pérez-Santos, C. \& A.G. Moreno. 1988. Ofidios de Colombia. Museo Regionale di Scienze Naturali, Torino, Italia.

Peters, J.A. \& R. Donoso-Barros. 1970. Catalogue of the neotropical squamata Part II: Lizards and amphisbaenians. Smithsonian, Washington. Bull. Unit. Stat. Nat. Mus. 297: 1-293.

Peters, J.A. \& B. Orejas-Miranda. 1970. Catalogue of the neotropical squamata Part I. Snakes. Bull. Unit. Stat. Nat. Mus. 297: 1-347. 
Pianka, E. 1967. On lizard species diversity: North American flatland deserts. Ecology 48: 333-351.

Pielou, E.C. 1975. Ecological Diversity. John Wiley \& Sons, Nueva York, EEUU.

Pineda, E. \& G. Halffter. 2004. Species diversity and habitat fragmentation: frogs in a tropical montane landscape in México. Biol. Conserv. 117: 499-508.

Pough, F.H. 1980. The advantages of ectothermy for tetrapods. Am. Nat. 115: 92-112.

Pough, F., R. Andrews, J. Cadle, M. Crump, A. Savitzky \& K. Wells. 1998. Herpetology. Prentice Hall, Nueva Jersey, EEUU.

Rangel-Ch., J.O., P. Lowy-C. \& M. Aguilar. 1997. Colombia Diversidad Biótica II: Tipos de Vegetación de Colombia. Instituto de Ciencias Naturales. Universidad Nacional de Colombia-IDEAM, Bogotá D.C., Colombia.

Rangel-Ch., J.O. 2000. Amenazas sobre la flora, la vegetación y los ecosistemas de Colombia. Pérez-Arbelaezia 5: 20-29.

Rangel-Ch., J.O. 2008. (ed.). Estudio de inventario de fauna y flora, descripción biofísica y línea base ambiental Ciénaga de Zapatosa. Convenio interadministrativo CORPOCESAR-Universidad Nacional de Colombia. Facultad de Ciencias. Instituto de Ciencias Naturales. Grupo de Biodiversidad y Conservación. Bogotá D.C., Colombia.

Rangel-Ch., J. O., J. E. Carvajal-Cogollo \& H. Arellano. 2008a. Clima, p. 61-98. In J. O. Rangel-Ch (ed.). Estudio de inventario de fauna y flora, descripción biofísica y línea base ambiental Ciénaga de Zapatosa. Convenio interadministrativo CORPOCESARUniversidad Nacional de Colombia. Facultad de Ciencias. Instituto de Ciencias Naturales. Grupo de Biodiversidad y Conservación. Bogotá D. C., Colombia. (Documento inédito). 500 pp.

Rangel-Ch., J.O, H. Garay-Púlido, E. Herrera \& A. AvellaMuñoz. 2008b. Bosques húmedos y secos circundantes a los complejos de humedales de la ciénaga de Zapatosa, departamento del Cesar, p. 98-205. In J.O. Rangel-Ch. (ed.). Estudio de inventario de fauna y flora, descripción biofísica y línea base ambiental Ciénaga de Zapatosa. Convenio interadministrativo CORPOCESAR-Universidad Nacional de Colombia. Facultad de Ciencias. Instituto de Ciencias Naturales. Grupo de Biodiversidad y Conservación. Bogotá D.C., Colombia.

Redford, K.H. 1997. A Floresta Vazia, p. 1-22. In C. Valladares-Padua, R.E. Bodmer \& L. Cullen Jr. (eds.).
Manejo e Conservação de Vida Silvestre no Brasil. Sociedade Civil Mamirauá, Belém.

Renjifo, J.M. \& M. Lundberg. 1999. Anfibios y reptiles de Urrá. Guía de campo. Colina, Medellín, Colombia.

Rengifo, J.T., J.A. Perea, A.M. Jiménez, J.M. Rengifo \& A.A. Castro. 2002. Ecología y estructura taxonómica de la "comunidad" de reptiles. Granja Universidad Tecnológica del Chocó, municipio de Lloró. Rev. Inst. Univ. Tec. Chocó 16: 47-52.

Ricklefs, R.E. \& D. Schluter. 1993. Species diversity: regional and historical influences, p. 350-363. In R.E. Ricklefs \& D. Schulter (eds.). Species diversity in ecological communities: historical and geographical perspectives. The University of Chicago, Chicago, EEUU.

Ríos-López, N. \& T. Mitchell. 2007. Herpetofaunal dynamics during secondary succession. Herpetologica 63: $35-50$.

Rodríguez, P. \& H.T. Arita. 2005. La diversidad beta como un elemento integrador de distintos patrones macroecológicos, p. 41-52. In G. Halffter, J. Soberón, P. Koleff \& A. Melic (eds.). Sobre diversidad biológica: el significado de las diversidades alfa, beta y gamma. Monografías Tercer Milenio, SEA, Zaragoza, España.

Rueda-Almonacid, J.V., A.A. Velásquez, P.A. Galvis \& J. Gualdrón. 2008. Reptiles, p. 193-268. In J.V. Rodríguez-Mahecha, J.V. Rueda-Almonacid \& T.D. Gutiérrez (eds.). Guía ilustrada de fauna del Santuario de Vida Silvestre Los Besotes, Valledupar, Cesar, Colombia. Serie de guías tropicales de campo No 7. Conservación Internacional-Colombia. Editorial Panamericana, Formas e Impresos. Bogotá D.C., Colombia.

Rugiero, L. \& L. Luiselli. 1995. Food habits of the snake Coluber viridiflavus in relation to prey availability. Amphibia-Reptilia 16: 407-411.

Sánchez-C, H., O.V. Castaño-Mora \& G. Cárdenas-A. 1995. Diversidad de los Reptiles en Colombia, p. 277-325. In J.O. Rangel-Ch. (ed.). Colombia Diversidad Biótica I. Instituto de Ciencias Naturales, Universidad Nacional de Colombia, Bogotá D.C., Colombia.

Sánchez-P., M.P. Rivas \& A. Cadena. 1996. Diversidad ecológica de una comunidad de quirópteros y su relación con la estructura del hábitat de bosque de galería, serranía de la Macarena, Colombia. Caldasia 18: 343-354.

Shine, R. \& X. Bonnet. 2000. Snakes: a new 'model organism' in ecological research? Trends Ecol. Evol. 15: 221-222. 
Smith, G.R. \& R.E. Ballinger. 2001. The ecological consequences of habitat and microhabitat use in Lizards: a review. Contemp. Herpetol. 3: 1-32.

Soberón, J.M. \& J. Llorente. 1993. The use of species accumulation functions for the prediction of species richness. Conserv. Biol. 7: 480-488.

Torres-Carvajal, O.M. 2007. A Taxonomic revision of South American Stenocercus (Squamata: Iguania) lizards. Herpetol. Monogr. 21: 76-178.

Urbina-Cardona, J.N. 2007. Evaluación del efecto de borde sobre la composición de la comunidad de herpetofauna en áreas con diferente uso del suelo y orientación del borde en la Reserva Los Tuxtlas, Veracruz. Ph.D. Tesis, Universidad Nacional Autónoma de México, México D.F., México.

Urbina-Cardona, J.N. \& M.C. Londoño-Murcia. 2003. Distribución de la comunidad de herpetofauna asociada a cuatro áreas con diferente grado de perturbación en la Isla Gorgona, Pacífico Colombiano. Rev. Acad. Colomb. Cienc. Exactas, Fis. Nat. 27: 105-113.

Urbina-Cardona, J.N. \& V.H. Reynoso 2005. Recambio de anfibios y reptiles en el gradiente potrero-bordeinterior en Los Tuxtlas, Veracruz, México, p. 191207. In G. Halffter, J. Soberón, P. Koleff \& A. Melic (eds.). Sobre diversidad biológica: el significado de las diversidades alfa, beta y gamma. Monografías Tercer Milenio, SEA, Zaragoza, España.

Urbina-Cardona, J.N., M.I. Olivares-Pérez \& V.H. Reynoso. 2006. Herpetofauna diversity and microenvironment correlates across the pasture-edge-interior ecotone in tropical rainforest fragments in the Los Tuxtlas Biosphere Reserve of Veracruz, México. Biol. Conserv. 132: 61-75.
Urbina-Cardona, J.N., M.C. Londoño-Murcia \& D.G. García-Ávila. 2008. Dinámica espacio-temporal en la diversidad de especies de serpientes en cuatro hábitats con diferente grado de alteración antropogénica en el Parque Nacional Natural Isla Gorgona, Pacífico Colombiano. Caldasia 30: 479-493.

Vargas, F. \& M.E. Bolaños. 1999. Anfibios y reptiles presentes en hábitats perturbados de selva tropical en el bajo Anchicayá, Pacífico Colombiano. Rev. Acad. Colomb. Cienc. Exactas, Fis. Nat. 23: 499-51.

Vitt, L.J. \& L.D. Vangilder. 1983. Ecology of a snake community in north-eastern Brazil. Amphibia-Reptilia 4: 273-296.

Vitt, L.J., P.A. Zani, J.P. Caldwell, M.C. De Araújo \& W.E. Magnusson. 1997. Ecology of whiptail lizards (Cnemidophorus) in the Amazon region of Brazil. Copeia 1997: 745-757.

Vitt, L.J. \& E.R. Pianka. 2004. Historical Patterns in Lizard Ecology: What teiids can tell us about lacertids, p.139-157. In V. Pérez-Mellado, N. Riera \& A. Perera (eds.). The Biology of lacertid lizards: Evolutionary and ecological perspectives. Institut Menorquí d'Estudis. Recerca 8, Menorca, España.

Vitt, L.J. \& E.R. Pianka. 2005. Deep history impacts present-day ecology and biodiversity. P. Natl. Acad. Sci. USA. 102: 7877-7881.

Whittaker, R.H. 1972. Evolution and measurement of species diversity. Taxon 21: 213-251.

Zar, J.H. 1998. Biostatistical analysis. Prentice Hall, Nueva Jersey, EEUU.

Zug, G.R., L.J. Vitt \& J.P. Caldwell. 2001. Herpetology: An introductory biology of amphibians and reptiles. Academic, Nueva York, EEUU. 
APÉNDICE 1

Comparación de la fauna de reptiles en las ciénagas de Zapatosa, Mata de Palma y La Pachita frente a otros estudios

(Referencias en Materiales y métodos)

\section{APPENDIX 1}

Comparison of the fauna of reptiles in the Zapatosa's wetland complex compared to other studies

(To look at references in Materials and methods)

\begin{tabular}{|c|c|c|c|c|c|c|c|c|c|}
\hline \multicolumn{10}{|c|}{ Reptiles } \\
\hline Orden & Familias & Especies & A & $\mathrm{B}$ & $\mathrm{C}$ & $\mathrm{D}$ & $\mathrm{E}$ & $\mathrm{F}$ & G \\
\hline \multirow[t]{2}{*}{ Crocodylia } & Crocodylidae & Caiman crocodilus & $\mathrm{X}$ & $X$ & & $\mathrm{X}$ & & & \\
\hline & & Crocodylus acutus & $\mathrm{X}$ & & & $\mathrm{X}$ & & & \\
\hline \multirow[t]{37}{*}{ Squamata } & Amphisbaenidae & Amphisbaena alba & & & $\mathrm{X}$ & & & & $\mathrm{X}$ \\
\hline & & Amphisbaena fuliginosa & & & & & & & $\mathrm{X}$ \\
\hline & & Amphisbaena medemi & & & & $\mathrm{X}$ & & & $\mathrm{X}$ \\
\hline & Anomalepididae & Liotyphlops albirostris & & $\mathrm{X}$ & & $\mathrm{X}$ & & & \\
\hline & Boidae & Boa constrictor & $\mathrm{X}$ & $\mathrm{X}$ & & $\mathrm{X}$ & $\mathrm{X}$ & $\mathrm{X}$ & $\mathrm{X}$ \\
\hline & & Corallus caninus & & & & $\mathrm{X}$ & & & \\
\hline & & Corallus ruschenbergerii & $\mathrm{X}$ & $X$ & $\mathrm{X}$ & $\mathrm{X}$ & & $\mathrm{X}$ & \\
\hline & & Epicrates cechria & $\mathrm{X}$ & $\mathrm{X}$ & & $\mathrm{X}$ & & $\mathrm{X}$ & \\
\hline & Colubridae & Chironius carinatus & $\mathrm{X}$ & $\mathrm{X}$ & & $\mathrm{X}$ & & $\mathrm{X}$ & \\
\hline & & Clelia clelia & & $\mathrm{X}$ & & $\mathrm{X}$ & & $\mathrm{X}$ & $\mathrm{X}$ \\
\hline & & Dendrophidium bivittatus & & & & $\mathrm{X}$ & & & \\
\hline & & Dendrophidium percarinatus & & & & $\mathrm{X}$ & & $\mathrm{X}$ & \\
\hline & & Drymarchon melanurus & & & & & & & $\mathrm{X}$ \\
\hline & & Erythrolamprus bizona & & $\mathrm{X}$ & $\mathrm{X}$ & & & & $\mathrm{X}$ \\
\hline & & Enulius flavitorques & $X$ & $X$ & & $\mathrm{X}$ & & & $\mathrm{X}$ \\
\hline & & Helicops danieli & $\mathrm{X}$ & $\mathrm{X}$ & & $\mathrm{X}$ & & & \\
\hline & & Helicops scalaris & & & & $\mathrm{X}$ & & & \\
\hline & & Imantodes cenchoa & $\mathrm{X}$ & $\mathrm{X}$ & $\mathrm{X}$ & $\mathrm{X}$ & & $\mathrm{X}$ & $\mathrm{X}$ \\
\hline & & Imantodes gemmistratus & $\mathrm{X}$ & & & & & & \\
\hline & & Leptodeira annulata & & & & $\mathrm{X}$ & $\mathrm{X}$ & & $\mathrm{X}$ \\
\hline & & Leptodeira septentrionalis & $\mathrm{X}$ & $\mathrm{X}$ & $\mathrm{X}$ & $\mathrm{X}$ & & $\mathrm{X}$ & \\
\hline & & Leptophis ahaetulla & $\mathrm{X}$ & $\mathrm{X}$ & $\mathrm{X}$ & $\mathrm{X}$ & $\mathrm{X}$ & $\mathrm{X}$ & $\mathrm{X}$ \\
\hline & & Liophis epinephelus & & & & $\mathrm{X}$ & & & \\
\hline & & Liophis lineatus & $\mathrm{X}$ & $\mathrm{X}$ & & $\mathrm{X}$ & & $\mathrm{X}$ & $\mathrm{X}$ \\
\hline & & Liophis melanotus & & $\mathrm{X}$ & $\mathrm{X}$ & $\mathrm{X}$ & & & $\mathrm{X}$ \\
\hline & & Mastigodryas boddaerti & & & & $\mathrm{X}$ & $\mathrm{X}$ & $\mathrm{X}$ & $\mathrm{X}$ \\
\hline & & Mastigodryas pleei & $\mathrm{X}$ & $\mathrm{X}$ & & $\mathrm{X}$ & & $\mathrm{X}$ & $\mathrm{X}$ \\
\hline & & Ninia atrata & & & & $\mathrm{X}$ & & & \\
\hline & & Oxybelis aeneus & $\mathrm{X}$ & $\mathrm{X}$ & $\mathrm{X}$ & $\mathrm{X}$ & & $\mathrm{X}$ & $\mathrm{X}$ \\
\hline & & Oxyrhopus petola & & $X$ & & $X$ & & $\mathrm{X}$ & \\
\hline & & Phimophis guianensis & $\mathrm{X}$ & $\mathrm{X}$ & & $\mathrm{X}$ & & $\mathrm{X}$ & $\mathrm{X}$ \\
\hline & & Pliocercus euryzonus & & & & $\mathrm{X}$ & & & \\
\hline & & Pseudoboa neuwiedii & $\mathrm{X}$ & $\mathrm{X}$ & $\mathrm{X}$ & $\mathrm{X}$ & $\mathrm{X}$ & $\mathrm{X}$ & \\
\hline & & Pseustes poecilonotus & & & & $\mathrm{X}$ & & & \\
\hline & & Pseustes shropshirei & & & & $\mathrm{X}$ & & & \\
\hline & & Rhadinaea fulviceps & & & & & $\mathrm{X}$ & & \\
\hline & & Rhinobothryum bovallii & & & & & & $\mathrm{X}$ & \\
\hline
\end{tabular}


APÉNDICE 1 (Continuación) / APPENDIX 1 (Continued)

\begin{tabular}{|c|c|c|c|c|c|c|c|c|c|}
\hline \multicolumn{10}{|c|}{ Reptiles } \\
\hline Orden & Familias & Especies & A & B & $\mathrm{C}$ & $\mathrm{D}$ & $\mathrm{E}$ & $\mathrm{F}$ & G \\
\hline & & Sibon nebulata & & $\mathrm{X}$ & $\mathrm{X}$ & $\mathrm{X}$ & & $\mathrm{X}$ & \\
\hline & & Spilotes pullatus & $\mathrm{X}$ & $\mathrm{X}$ & & $\mathrm{X}$ & & $\mathrm{X}$ & $\mathrm{X}$ \\
\hline & & Stenorrhina degenhardtii & & & & $\mathrm{X}$ & $\mathrm{X}$ & $\mathrm{X}$ & \\
\hline & & Tantilla melanocephala & & $\mathrm{X}$ & $\mathrm{X}$ & & & $\mathrm{X}$ & $\mathrm{X}$ \\
\hline & & Tantilla semicincta & & & & & & & $\mathrm{X}$ \\
\hline & & Thamnodynastes gambotensis & $\mathrm{X}$ & $\mathrm{X}$ & $\mathrm{X}$ & & & $\mathrm{X}$ & \\
\hline & & Thamnodynastes pallidus & & & & $\mathrm{X}$ & & & \\
\hline & & Urotheca fulviceps & & & & & & $\mathrm{X}$ & \\
\hline & & Xenodon rabdocephalus & & & & $\mathrm{X}$ & & & \\
\hline & Elapidae & Micrurus camilae & & & & $\mathrm{X}$ & & & \\
\hline & & Micrurus dissoleucus & & & & $\mathrm{X}$ & & $\mathrm{X}$ & $\mathrm{X}$ \\
\hline & & Micrurus dumerilii & & $\mathrm{X}$ & $\mathrm{X}$ & $\mathrm{X}$ & & $\mathrm{X}$ & $\mathrm{X}$ \\
\hline & & Micrurus mipartitus & & & & $\mathrm{X}$ & & $\mathrm{X}$ & \\
\hline & Leptotyphlopidae & Epictia dugandi & & & & & & & $\mathrm{X}$ \\
\hline & & Tricheilostoma goudotii & & & & & & & $\mathrm{X}$ \\
\hline & & Epictia macrolepis & & $\mathrm{X}$ & $\mathrm{X}$ & $\mathrm{X}$ & & & \\
\hline & Tropidophiidae & Trachyboa boulengeri & & & & $\mathrm{X}$ & & & \\
\hline & Viperidae & Bothriechis schlegelii & & & & $\mathrm{X}$ & & & \\
\hline & & Bothrops asper & $\mathrm{X}$ & $\mathrm{X}$ & $\mathrm{X}$ & $\mathrm{X}$ & $\mathrm{X}$ & $\mathrm{X}$ & $\mathrm{X}$ \\
\hline & & Crotalus durissus & $\mathrm{X}$ & & & $\mathrm{X}$ & & $\mathrm{X}$ & $\mathrm{X}$ \\
\hline & & Lachesis acrochorda & & & & $\mathrm{X}$ & & & \\
\hline & & Porthidium lansbergii & $\mathrm{X}$ & $\mathrm{X}$ & & $\mathrm{X}$ & & $\mathrm{X}$ & $\mathrm{X}$ \\
\hline & & Porthidium nasutum & & & & $\mathrm{X}$ & & & \\
\hline & Corytophanidae & Basiliscus basiliscus & $\mathrm{X}$ & $\mathrm{X}$ & & $\mathrm{X}$ & $\mathrm{X}$ & $\mathrm{X}$ & \\
\hline & & Basiliscus galeritus & & $\mathrm{X}$ & & $\mathrm{X}$ & & $\mathrm{X}$ & \\
\hline & & Corytophanes cristatus & & & $\mathrm{X}$ & $\mathrm{X}$ & & & \\
\hline & Gekkonidae & Gonatodes albogularis & $\mathrm{X}$ & $\mathrm{X}$ & $\mathrm{X}$ & $\mathrm{X}$ & $\mathrm{X}$ & $\mathrm{X}$ & $\mathrm{X}$ \\
\hline & & Hemidactylus brookii & & $\mathrm{X}$ & & $\mathrm{X}$ & & $\mathrm{X}$ & $\mathrm{X}$ \\
\hline & & Hemidactylus frenatus & $\mathrm{X}$ & $\mathrm{X}$ & & & & & \\
\hline & & Lepidoblepharis sanctaemartae & $\mathrm{X}$ & $\mathrm{X}$ & $\mathrm{X}$ & $\mathrm{X}$ & $\mathrm{X}$ & $\mathrm{X}$ & $\mathrm{X}$ \\
\hline & & Lepidoblepharis sp.1 & & & & & & $\mathrm{X}$ & \\
\hline & & Lepidoblepharis xanthostigma & & & & & & $\mathrm{X}$ & \\
\hline & & Sphaerodactylus heliconiae & $\mathrm{X}$ & & & & & $\mathrm{X}$ & \\
\hline & & Sphaerodactylus linoleatus & & & & $\mathrm{X}$ & & & \\
\hline & & Sphaerodactylus molei & & & & & & $\mathrm{X}$ & \\
\hline & & Thecadactylus rapicauda & $\mathrm{X}$ & $\mathrm{X}$ & & $\mathrm{X}$ & $\mathrm{X}$ & $\mathrm{X}$ & $\mathrm{X}$ \\
\hline & Gymnophthalmidae & Bachia bicolor & $\mathrm{X}$ & & $\mathrm{X}$ & $\mathrm{X}$ & $\mathrm{X}$ & $\mathrm{X}$ & \\
\hline & & Bachia talpa & & & & & & & $\mathrm{X}$ \\
\hline & & Gymnophthalmus speciosus & $\mathrm{X}$ & $X$ & $\mathrm{X}$ & $X$ & & $\mathrm{X}$ & $\mathrm{X}$ \\
\hline & & Leposoma rugiceps & $\mathrm{X}$ & $\mathrm{X}$ & $\mathrm{X}$ & $\mathrm{X}$ & $\mathrm{X}$ & $\mathrm{X}$ & \\
\hline & & Ptycoglossus festae & & & & $\mathrm{X}$ & & $\mathrm{X}$ & \\
\hline & & Tretioscincus bifasciatus & $\mathrm{X}$ & $\mathrm{X}$ & $\mathrm{X}$ & & $\mathrm{X}$ & $\mathrm{X}$ & $\mathrm{X}$ \\
\hline & Iguanidae & Iguana iguana & $\mathrm{X}$ & $\mathrm{X}$ & $\mathrm{X}$ & $\mathrm{X}$ & $\mathrm{X}$ & $\mathrm{X}$ & $\mathrm{X}$ \\
\hline & Polychrotidae & Anolis sp. 2 & & & & & & $\mathrm{X}$ & \\
\hline
\end{tabular}


APÉNDICE 1 (Continuación) / APPENDIX 1 (Continued)

\begin{tabular}{|c|c|c|c|c|c|c|c|c|c|}
\hline \multicolumn{10}{|c|}{ Reptiles } \\
\hline Orden & Familias & Especies & A & B & $\mathrm{C}$ & $\mathrm{D}$ & $\mathrm{E}$ & $\mathrm{F}$ & G \\
\hline & & Anolis auratus & $\mathrm{X}$ & $\mathrm{X}$ & $\mathrm{X}$ & $\mathrm{X}$ & $\mathrm{X}$ & $\mathrm{X}$ & $\mathrm{X}$ \\
\hline & & Anolis biporcatus & & $\mathrm{X}$ & $\mathrm{X}$ & $\mathrm{X}$ & & & \\
\hline & & Anolis chloris & & & & $\mathrm{X}$ & & & \\
\hline & & Anolis frenatus & & & & $X$ & & $\mathrm{X}$ & \\
\hline & & Anolis maculiventris & & & $\mathrm{X}$ & & & & \\
\hline & & Anolis mariarum & & $\mathrm{X}$ & $\mathrm{X}$ & & & & \\
\hline & & Anolis sulcifrons & & $\mathrm{X}$ & $\mathrm{X}$ & $\mathrm{X}$ & & $X$ & \\
\hline & & Anolis tropidogaster & $\mathrm{X}$ & $\mathrm{X}$ & $\mathrm{X}$ & $\mathrm{X}$ & & $\mathrm{X}$ & \\
\hline & & Anolis vittigerus & & $\mathrm{X}$ & $\mathrm{X}$ & $\mathrm{X}$ & & & \\
\hline & & Polychrus marmoratus & $\mathrm{X}$ & & & & $\mathrm{X}$ & $\mathrm{X}$ & $\mathrm{X}$ \\
\hline & Scincidae & Mabuya sp. & $\mathrm{X}$ & $\mathrm{X}$ & $\mathrm{X}$ & $\mathrm{X}$ & $\mathrm{X}$ & $\mathrm{X}$ & $\mathrm{X}$ \\
\hline & Teiidae & Ameiva ameiva & $\mathrm{X}$ & $\mathrm{X}$ & $\mathrm{X}$ & $\mathrm{X}$ & & $\mathrm{X}$ & $\mathrm{X}$ \\
\hline & & Ameiva bifrontata & & & & & $\mathrm{X}$ & $\mathrm{X}$ & \\
\hline & & Ameiva festiva & $\mathrm{X}$ & $\mathrm{X}$ & $\mathrm{X}$ & $\mathrm{X}$ & & $\mathrm{X}$ & \\
\hline & & Cnemidophorus lemniscatus & $\mathrm{X}$ & $\mathrm{X}$ & $\mathrm{X}$ & $X$ & $X$ & $\mathrm{X}$ & $\mathrm{X}$ \\
\hline & & Tupinambis teguixin & $\mathrm{X}$ & $\mathrm{X}$ & & $\mathrm{X}$ & $\mathrm{X}$ & & $\mathrm{X}$ \\
\hline & Tropiduridae & Stenocercus erythrogaster & $\mathrm{X}$ & & & & $\mathrm{X}$ & $\mathrm{X}$ & $\mathrm{X}$ \\
\hline \multirow[t]{10}{*}{ Testudinata } & Chelidae & Mesoclemmys dahli & $\mathrm{X}$ & $\mathrm{X}$ & & $\mathrm{X}$ & & & \\
\hline & Chelydridae & Chelydra acutirostris & & & & $\mathrm{X}$ & & & \\
\hline & Emydidae & Trachemys callirostris & $\mathrm{X}$ & $\mathrm{X}$ & & $\mathrm{X}$ & & & \\
\hline & Geoemydidae & Rhinoclemmys annulata & & & & $\mathrm{X}$ & & & \\
\hline & & Rhinoclemmys melanosterna & $\mathrm{X}$ & $\mathrm{X}$ & & $\mathrm{X}$ & & $\mathrm{X}$ & \\
\hline & Kinosternidae & Kinosternon leucostomum & & $\mathrm{X}$ & & $\mathrm{X}$ & & & \\
\hline & & Kinosternon scorpioides & $\mathrm{X}$ & $\mathrm{X}$ & & $\mathrm{X}$ & & $\mathrm{X}$ & $\mathrm{X}$ \\
\hline & Podocnemididae & Podocnemys lewyana & $\mathrm{X}$ & $\mathrm{X}$ & & $\mathrm{X}$ & & & \\
\hline & Testudinata & Chelonoidis carbonaria & $\mathrm{X}$ & $\mathrm{X}$ & $\mathrm{X}$ & $\mathrm{X}$ & & $\mathrm{X}$ & $\mathrm{X}$ \\
\hline & & Total & 48 & 56 & 35 & 82 & 23 & 60 & 44 \\
\hline
\end{tabular}

A: Complejo cenagoso de Zapatosa, B: Humedales de Córdoba, C: Bosques Relictuales de Córdoba, D: Revisión de bibliografía, E: La Jagua de Ibirico-Serranía de Perijá, F: Síntesis de fauna del Cesar, franja tropical y G: Reptiles-Santuario de vida silvestre Los Besotes

A: Zapatosa's wetland complex, B: Wetlands of Córdoba, C: Relict forest of Córdoba, D: Review of literature, E: La Jagua de Ibirico-Perijá, F: Summary of fauna Cesar' lowland and G: Reptiles-Wildlife Sanctuary the Besotes

\section{APÉNDICE 2}

Abundancia por hábitat y por especie de la fauna de reptiles en el complejo cenagoso de Zapatosa, departamento del Cesar (Colombia)

\section{APPENDIX 2}

Abundance by habitat and wildlife species of reptiles in the Zapatosa's wetland complex, departmento del Cesar (Colombia)

\begin{tabular}{lccccccc}
\multicolumn{1}{r}{ ESPECIES* } & Código & BP & BS & BR & P & SA & No de individuos \\
Chironius carinatus & $\mathrm{a}$ & 0 & 1 & 2 & 1 & 0 & 4 \\
Helicops danieli & $\mathrm{b}$ & 0 & 0 & 3 & 1 & 3 & 7 \\
Imantodes cenchoa & $\mathrm{c}$ & 0 & 3 & 1 & 5 & 2 & 11
\end{tabular}


APÉNDICE 2 (Continuación) / APPENDIX 2 (Continued)

\begin{tabular}{|c|c|c|c|c|c|c|c|}
\hline ESPECIES* & Código & $\mathrm{BP}$ & BS & $\mathrm{BR}$ & $\mathrm{P}$ & SA & No de individuos \\
\hline Leptophis ahaetulla & $\mathrm{d}$ & 1 & 2 & 5 & 0 & 0 & 8 \\
\hline Leptodeira septentrionalis & $\mathrm{e}$ & 2 & 6 & 8 & 3 & 2 & 21 \\
\hline Liophis lineatus & $\mathrm{f}$ & 0 & 1 & 1 & 1 & 1 & 4 \\
\hline Mastigodryas pleei & $\mathrm{g}$ & 0 & 1 & 1 & 0 & 0 & 2 \\
\hline Oxybelis aeneus & $\mathrm{h}$ & 2 & 1 & 2 & 0 & 0 & 5 \\
\hline Phimophis guianensis & I & 1 & 0 & 2 & 0 & 0 & 3 \\
\hline Pseudoboa neuwiedii & $\mathrm{j}$ & 0 & 0 & 4 & 1 & 0 & 5 \\
\hline Spilotes pullatus & $\mathrm{k}$ & 1 & 0 & 0 & 0 & 0 & 1 \\
\hline Enulius flavitorques & 1 & 0 & 0 & 1 & 0 & 0 & 1 \\
\hline Thamnodynastes gambotensis & $\mathrm{m}$ & 0 & 5 & 3 & 6 & 2 & 16 \\
\hline Boa constrictor & $\mathrm{n}$ & 0 & 1 & 0 & 0 & 1 & 2 \\
\hline Corallus ruschenbergerii & o & 0 & 2 & 1 & 2 & 2 & 7 \\
\hline Epicrates cechria & $\mathrm{p}$ & 0 & 0 & 1 & 0 & 0 & 1 \\
\hline Bothrops asper & $\mathrm{q}$ & 0 & 0 & 6 & 0 & 2 & 8 \\
\hline Crotalus durissus & $\mathrm{r}$ & 0 & 0 & 0 & 0 & 2 & 2 \\
\hline Porthidium lansbergii & $\mathrm{s}$ & 0 & 0 & 3 & 0 & 0 & 3 \\
\hline Basiliscus basiliscus & $\mathrm{t}$ & 2 & 5 & 5 & 14 & 0 & 26 \\
\hline Iguana iguana & $\mathrm{u}$ & 5 & 12 & 3 & 3 & 5 & 28 \\
\hline Anolis auratus & $\mathrm{v}$ & 19 & 25 & 10 & 31 & 20 & 105 \\
\hline Anolis tropidogaster & $\mathrm{w}$ & 35 & 25 & 45 & 20 & 1 & 126 \\
\hline Polychrus marmoratus & $\mathrm{x}$ & 0 & 0 & 1 & 1 & 2 & 4 \\
\hline Stenocercus erythrogaster & $\mathrm{y}$ & 13 & 0 & 0 & 0 & 0 & 13 \\
\hline Mabuya sp. & $\mathrm{z}$ & 4 & 1 & 6 & 1 & 5 & 17 \\
\hline Gonatodes albogularis & A & 33 & 31 & 33 & 38 & 6 & 141 \\
\hline Lepidoblepharis sanctaemartae & $\mathrm{B}$ & 8 & 15 & 4 & 2 & 2 & 31 \\
\hline Sphaerodactylus heliconiae & $\mathrm{C}$ & 0 & 0 & 2 & 0 & 0 & 2 \\
\hline Thecadactylus rapicaudus & $\mathrm{D}$ & 1 & 7 & 6 & 6 & 4 & 24 \\
\hline Gymnophthalmus speciosus & $\mathrm{F}$ & 0 & 0 & 1 & 2 & 0 & 3 \\
\hline Leposoma rugiceps & G & 0 & 2 & 0 & 2 & 0 & 4 \\
\hline Tretioscincus bifasciatus & $\mathrm{H}$ & 3 & 4 & 6 & 8 & 0 & 21 \\
\hline Cnemidophorus lemniscatus & I & 5 & 15 & 10 & 10 & 30 & 70 \\
\hline Ameiva ameiva & $\mathrm{J}$ & 0 & 10 & 3 & 5 & 21 & 39 \\
\hline Ameiva festiva & $\mathrm{K}$ & 0 & 2 & 8 & 1 & 5 & 16 \\
\hline Tupinambis teguixin & $\mathrm{L}$ & 0 & 0 & 4 & 5 & 2 & 11 \\
\hline Trachemys callirostris & M & 0 & 1 & 0 & 0 & 4 & 5 \\
\hline Kinosternon scorpioides & $\mathrm{N}$ & 1 & 0 & 2 & 1 & 0 & 4 \\
\hline Chelonoidis carbonaria & $\mathrm{O}$ & 0 & 0 & 0 & 1 & 0 & 1 \\
\hline Caiman crocodilus & $\mathrm{P}$ & 0 & 5 & 3 & 0 & 2 & 10 \\
\hline Abundancia por hábitat & & 136 & 183 & 196 & 171 & 126 & 812 \\
\hline
\end{tabular}

BP: Bosque casmófito, BS: Bosque seco, P: Palmar, BR: Bosque de ribera y SA: Sabanas arboladas.

* Se excluyeron las 7 especies y 45 individuos ya mencionados

BP: chasmophyte forest, BS: dry forest, P: palm-grove, BR: riparian forest and SA: tree-lined savanna.

* Seven species and 45 individuals were excluded 
APÉNDICE 3

Valores de los estimadores de riqueza y la representatividad del muestreo para todas las especies de reptiles, en cada hábitat en general, por grupos taxonómicos (serpientes y saurios) en cada uno de los hábitats muestreados en el complejo ciénaga de Zapatosa

APPENDIX 3

Values of the estimates of richness and completeness sampling for all species of reptiles, in each habitat in general, and taxa (snakes and lizards) in each of the habitats sampled in the Zapatosa's wetland complex

\begin{tabular}{|c|c|c|c|c|c|}
\hline \multicolumn{6}{|c|}{ EN GENERAL TODO EL ESTUDIO PARA TODAS LAS ESPECIES } \\
\hline Sp obs (Mao Tau) & Únicas & Duplicadas & Jack 1 & Jack 2 & Bootstrap \\
\hline 7.48 & 7.48 & 0 & 7.48 & 0 & 7.48 \\
\hline 12.65 & 10.24 & 2.37 & 17.73 & 17.73 & 15.17 \\
\hline 16.48 & 11.49 & 3.98 & 24.12 & 27.28 & 20.01 \\
\hline 19.47 & 11.84 & 5.2 & 28.34 & 32.53 & 23.54 \\
\hline 21.89 & 12.05 & 5.75 & 31.53 & 36.17 & 26.31 \\
\hline 23.9 & 12.13 & 6.11 & 34.05 & 38.88 & 28.6 \\
\hline 25.61 & 12.1 & 6.29 & 36.08 & 40.98 & 30.49 \\
\hline 27.09 & 11.89 & 6.6 & 37.6 & 42.27 & 32.03 \\
\hline 28.37 & 11.76 & 6.66 & 38.94 & 43.56 & 33.38 \\
\hline 29.51 & 11.56 & 6.84 & 40.07 & 44.46 & 34.56 \\
\hline 30.52 & 11.32 & 6.88 & 40.96 & 45.15 & 35.54 \\
\hline 31.42 & 11.03 & 6.92 & 41.64 & 45.58 & 36.36 \\
\hline 32.23 & 10.7 & 7.04 & 42.2 & 45.79 & 37.08 \\
\hline 32.96 & 10.42 & 7.09 & 42.72 & 46.05 & 37.74 \\
\hline 33.63 & 10.13 & 7.16 & 43.19 & 46.21 & 38.37 \\
\hline 34.23 & 9.79 & 7.23 & 43.53 & 46.19 & 38.89 \\
\hline 34.78 & 9.48 & 7.23 & 43.8 & 46.18 & 39.34 \\
\hline 35.29 & 9.16 & 7.17 & 44.03 & 46.18 & 39.73 \\
\hline 35.76 & 8.88 & 7.13 & 44.27 & 46.2 & 40.14 \\
\hline 36.19 & 8.6 & 7.04 & 44.45 & 46.19 & 40.46 \\
\hline 36.59 & 8.4 & 6.85 & 44.68 & 46.39 & 40.8 \\
\hline 36.96 & 8.16 & 6.69 & 44.84 & 46.47 & 41.07 \\
\hline 37.3 & 7.96 & 6.53 & 45.02 & 46.59 & 41.35 \\
\hline 37.62 & 7.76 & 6.36 & 45.14 & 46.68 & 41.57 \\
\hline 37.92 & 7.57 & 6.15 & 45.3 & 46.84 & 41.81 \\
\hline 38.21 & 7.35 & 5.94 & 45.36 & 46.87 & 41.98 \\
\hline 38.49 & 7.19 & 5.71 & 45.45 & 47.02 & 42.14 \\
\hline 38.72 & 7.05 & 5.51 & 45.59 & 47.21 & 42.34 \\
\hline 38.96 & 6.9 & 5.29 & 45.68 & 47.37 & 42.49 \\
\hline 39.19 & 6.75 & 5.16 & 45.76 & 47.4 & 42.63 \\
\hline 39.41 & 6.64 & 5 & 45.86 & 47.55 & 42.77 \\
\hline 39.61 & 6.56 & 4.8 & 46.01 & 47.8 & 42.94 \\
\hline 39.81 & 6.48 & 4.69 & 46.15 & 47.97 & 43.1 \\
\hline 40 & 6.42 & 4.57 & 46.27 & 48.14 & 43.23 \\
\hline 40.19 & 6.36 & 4.48 & 46.38 & 48.28 & 43.36 \\
\hline 40.36 & 6.33 & 4.44 & 46.55 & 48.45 & 43.52 \\
\hline 40.53 & 6.23 & 4.52 & 46.62 & 48.36 & 43.63 \\
\hline 40.69 & 6.17 & 4.59 & 46.71 & 48.32 & 43.74 \\
\hline 40.85 & 6.11 & 4.74 & 46.8 & 48.21 & 43.87 \\
\hline 41 & 6 & 5 & 46.85 & 47.92 & 43.98 \\
\hline Represent. (\%) & & & 87,5 & 85,6 & 93,2 \\
\hline
\end{tabular}


APÉNDICE 3 (Continuación) / APPENDIX 3 (Continued)

\begin{tabular}{|c|c|c|c|c|c|}
\hline Sp obs (Mao Tau) & Únicas & Duplicadas & ICE & Chao 2 & Bootstrap \\
\hline \multicolumn{6}{|c|}{ EN GENERAL TODO EL ESTUDIO PARA TODOS LOS LAGARTOS } \\
\hline Represent. (\%) & & & 94.8 & 94.7 & 97.1 \\
\hline \multicolumn{6}{|c|}{ EN GENERAL TODO EL ESTUDIO PARA TODAS LAS SERPIENTES } \\
\hline Represent. (\%) & & & 83.0 & 82.6 & 90.3 \\
\hline
\end{tabular}

\begin{tabular}{|c|c|c|c|c|c|}
\hline \multicolumn{6}{|c|}{ PARA CADA UNO DE LOS HÁBITATS } \\
\hline \multicolumn{6}{|c|}{ BP PARA TODAS LAS ESPECIES } \\
\hline Sp obs (Mao Tau) & Únicas & Duplicadas & ICE & Chao 2 & Bootstrap \\
\hline 5.75 & 5.8 & 0 & 18.92 & 18.92 & 5.8 \\
\hline 9.21 & 7.13 & 2.23 & 44.78 & 17.67 & 11.14 \\
\hline 11.52 & 7.05 & 3.5 & 25.2 & 16.8 & 13.87 \\
\hline 13.16 & 6.58 & 4.01 & 21.8 & 17.64 & 15.54 \\
\hline 14.39 & 6.15 & 4.12 & 20.87 & 17.88 & 16.78 \\
\hline 15.39 & 6 & 3.58 & 21 & 18.86 & 17.78 \\
\hline 16.25 & 6.02 & 3.01 & 21.58 & 20.79 & 18.67 \\
\hline 17 & 6 & 3 & 21.98 & 20.28 & 19.42 \\
\hline \multicolumn{6}{|c|}{ BP PARA TODOS LOS LAGARTOS } \\
\hline Represent. (\%) & & & 92.4 & 96.2 & 95.7 \\
\hline \multicolumn{6}{|c|}{ BP PARA TODAS LAS SERPIENTES } \\
\hline Represent. (\%) & & & 57.1 & 85.0 & 83.3 \\
\hline \multicolumn{6}{|c|}{ BS PARA TODAS LAS ESPECIES } \\
\hline Sp obs (Mao Tau) & Únicas & Duplicadas & ICE & Chao 2 & Bootstrap \\
\hline 8 & 8.02 & 0 & 34.79 & 34.79 & 8.02 \\
\hline 13.11 & 10.3 & 2.8 & 65.8 & 33.23 & 15.68 \\
\hline 16.61 & 10.56 & 4.8 & 43.76 & 27.22 & 19.96 \\
\hline 19.19 & 10.36 & 5.56 & 33.96 & 27.01 & 22.87 \\
\hline 21.18 & 10 & 5.85 & 32.62 & 28.09 & 24.98 \\
\hline 22.75 & 9.52 & 6.28 & 32.2 & 28.81 & 26.61 \\
\hline 24 & 8.8 & 6.66 & 31.74 & 28.63 & 27.73 \\
\hline 25 & 8 & 7 & 31.24 & 28.06 & 28.55 \\
\hline \multicolumn{6}{|c|}{ BS PARA TODOS LOS LAGARTOS } \\
\hline Represent. (\%) & & & 93.3 & 98.3 & 98.1 \\
\hline \multicolumn{6}{|c|}{ BS PARA TODAS LAS SERPIENTES } \\
\hline Represent. (\%) & & & 65.8 & 85.1 & 83.3 \\
\hline \multicolumn{6}{|c|}{ P PARA TODAS LAS ESPECIES } \\
\hline Sp obs (Mao Tau) & Únicas & Duplicadas & ICE & Chao 2 & Bootstrap \\
\hline 7.75 & 7.79 & 0 & 32.83 & 32.83 & 7.79 \\
\hline 12.54 & 9.52 & 2.99 & 69.05 & 38.4 & 14.89 \\
\hline 16.07 & 10.52 & 3.8 & 43.34 & 38.18 & 19.32 \\
\hline 18.83 & 10.96 & 4.72 & 38.41 & 34.92 & 22.61 \\
\hline 21.09 & 11.19 & 4.98 & 37.73 & 36.6 & 25.13 \\
\hline 23 & 11.46 & 5.24 & 38.67 & 37.68 & 27.36 \\
\hline 24.63 & 11.36 & 6.01 & 39.03 & 35.89 & 29.12 \\
\hline 26 & 11 & 7 & 39.1 & 34.64 & 30.54 \\
\hline
\end{tabular}


APÉNDICE 3 (Continuación) / APPENDIX 3 (Continued)

\begin{tabular}{|c|c|c|c|c|c|}
\hline Sp obs (Mao Tau) & Únicas & Duplicadas & ICE & Chao 2 & Bootstrap \\
\hline \multicolumn{6}{|c|}{ P PARA TODOS LOS LAGARTOS } \\
\hline Represent. (\%) & & & 78.0 & 91.6 & 90.5 \\
\hline \multicolumn{6}{|c|}{ P PARA TODAS LAS SERPIENTES } \\
\hline Represent. (\%) & & & 69.9 & 82.1 & 80.0 \\
\hline \multicolumn{6}{|c|}{ BR PARA TODAS LAS ESPECIES } \\
\hline Sp obs (Mao Tau) & Únicas & Duplicadas & ICE & Chao 2 & Bootstrap \\
\hline 9.75 & 9.66 & 0 & 55.77 & 55.77 & 9.66 \\
\hline 16.54 & 13.42 & 2.91 & 111.77 & 43.12 & 19.69 \\
\hline 21.54 & 15.13 & 5.2 & 71.54 & 42.48 & 26.17 \\
\hline 25.31 & 15.22 & 7.29 & 54.73 & 40.3 & 30.52 \\
\hline 28.21 & 14.62 & 8.73 & 47.63 & 38.63 & 33.65 \\
\hline 30.5 & 13.81 & 9.13 & 44.88 & 39.07 & 36 \\
\hline 32.38 & 13.18 & 8.54 & 44.32 & 40.52 & 37.83 \\
\hline 34 & 13 & 7 & 45.05 & 42.53 & 39.39 \\
\hline \multicolumn{6}{|c|}{ BR PARA TODOS LOS LAGARTOS } \\
\hline Represent. (\%) & & & 87.4 & 90.1 & 88.9 \\
\hline \multicolumn{6}{|c|}{ BR PARA TODAS LAS SERPIENTES } \\
\hline Represent. (\%) & & & 64.5 & 76.6 & 74.1 \\
\hline \multicolumn{6}{|c|}{ SA PARA TODAS LAS ESPECIES } \\
\hline Sp obs (Mao Tau) & Únicas & Duplicadas & ICE & Chao 2 & Bootstrap \\
\hline 6.13 & 6.42 & 0 & 27.07 & 27.07 & 6.42 \\
\hline 10.61 & 9.11 & 1.7 & 68.03 & 26.91 & 13.09 \\
\hline 14.05 & 10.51 & 3.12 & 52.55 & 28.39 & 17.51 \\
\hline 16.79 & 11.03 & 4.35 & 40.39 & 28.02 & 20.71 \\
\hline 18.96 & 10.95 & 5.58 & 35.35 & 27.19 & 23.13 \\
\hline 20.68 & 10.24 & 7.01 & 32.51 & 26.5 & 24.78 \\
\hline 22 & 9.25 & 8.25 & 30.86 & 26.08 & 25.98 \\
\hline 23 & 8 & 9 & 29.44 & 25.45 & 26.74 \\
\hline \multicolumn{6}{|c|}{ SA PARA TODOS LOS LAGARTOS } \\
\hline Represent. (\%) & & & 78.1 & 90.2 & 88.9 \\
\hline \multicolumn{6}{|c|}{ SA PARA TODAS LAS SERPIENTES } \\
\hline Represent. (\%) & & & 80.0 & 95.9 & 95.4 \\
\hline
\end{tabular}

BP: Bosque casmófito, BS: Bosque seco, P: Palmar, BR: Bosque de ribera y SA: Sabanas arboladas.

BP: chasmophyte forest, BS: dry forest, P: palm-grove, BR: riparian forest and SA: tree-lined savanna. 